\title{
Benthic Carbon Mineralization and Nutrient Turnover in a Scottish Sea Loch: An Integrative In Situ Study
}

\author{
Ronnie N. Glud ${ }^{1,2,3}(\mathbb{D}) \cdot$ Peter Berg $^{4} \cdot$ Henrik Stahl $^{2,5}$ • \\ Andrew Hume ${ }^{2}$ Morten Larsen ${ }^{1,2}$ - Bradley D. Eyre ${ }^{6}$. \\ Perran L. M. $\operatorname{Cook}^{7}$
}

Received: 8 March 2016/ Accepted: 22 August 2016/Published online: 8 September 2016

(C) The Author(s) 2016. This article is published with open access at Springerlink.com

\begin{abstract}
Based on in situ microprofiles, chamber incubations and eddy covariance measurements, we investigated the benthic carbon mineralization and nutrient regeneration in a 65-m-deep sedimentation basin of Loch Etive, UK. The sediment hosted a considerable amount of infauna that was dominated by the brittle star A. filiformis. The numerous burrows were intensively irrigated enhancing the benthic in situ $\mathrm{O}_{2}$ uptake by $\sim 50 \%$, and inducing highly variable redox conditions and $\mathrm{O}_{2}$ distribution in the surface sediment as also documented by complementary laboratory-based planar optode measurements. The average benthic $\mathrm{O}_{2}$ exchange as derived by chamber incubations and the eddy covariance approach were similar $\left(14.9 \pm 2.5\right.$ and $\left.13.1 \pm 9.0 \mathrm{mmol} \mathrm{m}^{-2} \mathrm{day}^{-1}\right)$ providing confidence in the two measuring approaches. Moreover, the non-invasive eddy approach revealed a flow-dependent benthic $\mathrm{O}_{2}$ flux that was partly ascribed to enhanced ventilation of infauna burrows during periods of elevated flow rates. The ratio in exchange rates of $\Sigma \mathrm{CO}_{2}$ and $\mathrm{O}_{2}$ was close to unity, confirming that the $\mathrm{O}_{2}$ uptake was a good proxy for the benthic carbon mineralization in this setting. The infauna activity resulted in highly dynamic redox conditions that presumably facilitated an efficient degradation of both
\end{abstract}

Electronic supplementary material The online version of this article (doi:10.1007/s10498-016-9300-8) contains supplementary material, which is available to authorized users.

Ronnie N. Glud

rnglud@biology.sdu.dk

1 Nordic Centre for Earth Evolution, University of Southern Denmark, Odense, Denmark

2 Scottish Marine Institute, Scottish Association for Marine Science, Oban, UK

3 Arctic Research Centre, University of Aarhus, Aarhus, Denmark

4 Department of Environmental Sciences, University of Virginia, Charlottesville, VA, USA

5 Zayed University, Dubai Academic City, Dubai, United Arab Emirates

6 Centre for Coastal Biogeochemistry Research, Southern Cross University, Lismore, NSW, Australia

7 Water Studies Centre, School of Chemistry, Monash University, Clayton, VIC 3800, Australia 
terrestrial and marine-derived organic material. The complex $\mathrm{O}_{2}$ dynamics of the burrow environment also concurrently stimulated nitrification and coupled denitrification rates making the sediment an efficient sink for bioavailable nitrogen. Furthermore, bioturbation mediated a high efflux of dissolved phosphorus and silicate. The study documents a high spatial and temporal variation in benthic solute exchange with important implications for benthic turnover of organic carbon and nutrients. However, more long-term in situ investigations with like approaches are required to fully understand how environmental events and spatio-temporal variations interrelate to the overall biogeochemical functioning of coastal sediments.

Keywords Carbon cycle $\cdot$ Oxygen exchange $\cdot$ Nutrient regeneration $\cdot$ Denitrification $\cdot$ In situ measurements · Eddy covariance $\cdot$ Loch Etive

\section{Introduction}

The coastal zone interfaces the terrestrial and oceanic biomes and is generally characterized by intense biogeochemical cycling. Riverine run-off and occasional upwelling supply nutrition for intense biological production and despite only covering $\sim 7 \%$ of the ocean bed, coastal sediments are globally important sites for organic carbon mineralization, nutrient regeneration and carbon preservation (Nixon et al. 1996; Gattuso et al. 1998; Wollast 1993; Smith et al. 2015). However, coastal sediments are also characterized by an extensive temporal and spatial variability that complicate the assessment on their biogeochemical function and importance. Daily, seasonal and interannual variations in hydrography and weather strongly influence deposition, particle dynamics and near-bed hydrodynamics that all directly or indirectly regulate the relative importance of the respective diagenetic pathways and the total benthic mineralization rate (Thamdrup et al. 1994; Cathalot et al. 2010; Liu et al. 2014). Additionally, particulate deposition and fauna activity can induce considerable microscale spatial variation in the intensity and the nature of the dominant microbial processes (Thouzeau et al. 2007; Dedieu et al. 2007; Glud et al. 2009a; Aller 2014). The intense metabolic activity also induces steep concentration gradients of redox species, and this together with the dynamic nature of coastal environments challenges procedures for quantifying and characterizing the early diagenesis. While laboratory-based investigations can provide valuable insight on diagenetic processes, measurements of benthic solute exchange using cores and microcosms can be compromised by disturbances during sediment recovery and challenges in re-establishing natural environmental conditions in the laboratory. However, while there for some time has been considerable awareness on the necessity of in situ investigation for quantifying microbial processing in deep-sea sediments (Reimers et al. 1986; Jahnke et al. 1990; Glud et al. 1994; Smith et al. 1997) only more recently has the requirement for in situ investigations of coastal sediments been acknowledged (Jahnke and Jahnke 2008; Toussaint et al. 2014).

Arguably the most important parameters for assessing the biogeochemical functioning of marine sediments are the distribution and exchange of $\mathrm{O}_{2}$. Benthic $\mathrm{O}_{2}$ availability regulates key processes in nutrient cycling, and the sediment $\mathrm{O}_{2}$ consumption is the most widely applied proxy for quantifying the mineralization rate of organic carbon in sediments (Glud 2008). The underlying assumption behind this approach is that most reduced constituents from the anaerobic carbon degradation are concurrently oxidized by $\mathrm{O}_{2}$ (Canfield 
et al. 1993). This may not always be entirely correct, especially in reduced sediments (Anderson et al. 1986; Therkildsen and Lomstein 1993), but in most settings and when averaged over some time the $\mathrm{O}_{2}$ uptake represents a robust proxy for the total benthic mineralization rate. Therefore, there have been numerous studies quantifying the benthic $\mathrm{O}_{2}$ exchange rate applying a range of different measuring approaches (Glud 2008 and references therein).

The in situ total $\mathrm{O}_{2}$ exchange (TOE) of sediments is typically quantified from the measured decline in $\mathrm{O}_{2}$ concentration during chamber incubations. Chamber incubations also make it possible to quantify the concurrent release of dissolved inorganic carbon (DIC) and the net benthic exchange of nutrients. The TOE represents an integrated measure of the diffusive- and the fauna-mediated $\mathrm{O}_{2}$ consumption of a well-defined sediment area. However, measurements of $\mathrm{O}_{2}$ microprofiles enable a more detailed insight on the benthic $\mathrm{O}_{2}$ distribution and the quantification of the diffusive-mediated $\mathrm{O}_{2}$ exchange (DOE). Parallel chamber incubations and microprofile measurements therefore allow quantification of the fauna-mediated $\mathrm{O}_{2}$ uptake (Glud et al. 2003). Latest, eddy covariance has been introduced for quantifying the benthic $\mathrm{O}_{2}$ exchange rate (Berg et al. 2003). The approach derives the benthic $\mathrm{O}_{2}$ exchange rate from concurrent measurements of the near-bed fluctuations in the $\mathrm{O}_{2}$ concentrations and the vertical flow velocity without disturbing the sediment or natural drivers of the solute exchange. The eddy-derived $\mathrm{O}_{2}$ exchange (EOE) therefore integrates the $\mathrm{O}_{2}$ consumption across a large $\left(10-100 \mathrm{~m}^{2}\right)$, but variable upstream area of the seabed (Berg et al. 2007). The three in situ approaches are highly complementary, and combining the approaches provides the most detailed insight on environmental factors regulating the benthic $\mathrm{O}_{2}$ exchange rate that can be provided.

Here we explore the benthic $\mathrm{O}_{2}$ dynamics of cohesive, infauna-rich, coastal sediments applying all three measuring approaches. The in situ measurements are complemented by laboratory-based investigation of $\mathrm{O}_{2}$ dynamics around the dominant infauna using twodimensional planar optode technology and three-dimensional computer-aided tomography. Combined, the measurements provide an unparalleled insight into benthic $\mathrm{O}_{2}$ dynamics and governing factors in typical sea loch sediments. The insight is used to discuss implications for benthic carbon mineralization and nutrient turnover as inferred from concurrent in situ measurements of $\mathrm{NO}_{3}{ }^{-}$microprofiles and net exchange of $\mathrm{DIC}, \mathrm{NO}_{3}{ }^{-}$, $\mathrm{NH}_{4}{ }^{+}, \mathrm{PO}_{4}{ }^{3-}$, dissolved $\mathrm{Si}(\mathrm{DSi})$ and $\mathrm{N}_{2}$.

\section{Materials and Methods}

\subsection{Study Site and Sampling Campaigns}

Loch Etive is an approximately 30-km-long glacial fjord on the west coast of Scotland (Fig. 1). Sills create a series of smaller basins, but the fjord can conveniently be divided into two major basins (Fig. 1b, c; Edwards and Edelstein 1977). The fjord has a relatively high freshwater discharge which, in combination with shallow sills at Connel Narrows and Bonawe, leads to a relatively long residence time of the saltier bottom water of the two basins (Austin and Inall 2002; Overnell et al. 2002). The present work was conducted at Airds Bay $\left(56^{\circ} 27.334^{\prime} \mathrm{N} ; 5^{\circ} 14.248^{\prime} \mathrm{W}\right)$ in the better ventilated seaward lower basin (Fig. 1). The average depth of the depth recorder of the respective in situ instruments ranged between 56 and $70 \mathrm{~m}$ with an overall average of $65 \pm 4(n=18) \mathrm{m}$. During the study period (29 October-14 November 2008), the bottom water temperature and salinity 


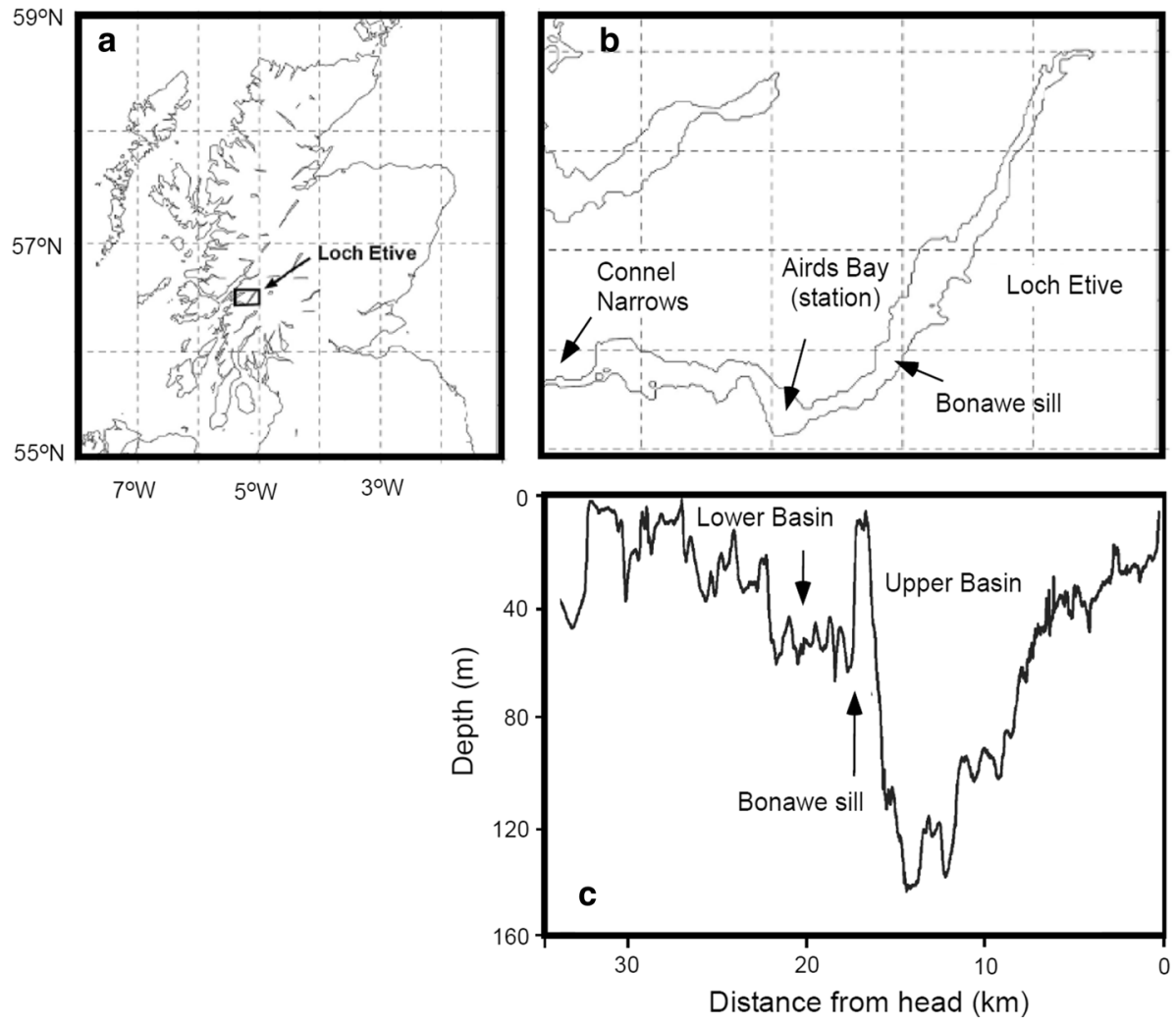

Fig. 1 a Map showing the location of Loch Etive in West Scotland, UK. b An enlargement of Loch Etive including the locations of the major sills at Connel Narrows and Bonawe enclosing the study site in Airds Bay. c Bathymetry of Loch Etive along the deepest points. a, b is modified from Inoue et al. (2011), while c is modified from Overnell et al. (2002)

remained at $13 \pm 0.5$ and $25 \pm 0.3{ }^{\circ} \mathrm{C}$, respectively. Tidal-induced mixing generally ensure that the seaward basin is relatively well oxygenated, but during the study period the measured bottom water $\mathrm{O}_{2}$ concentration tended to decline from $181 \pm 2$ to $171 \pm 3 \mu \mathrm{mol} \mathrm{L}{ }^{-1}$ and the overall average value was $174 \pm 5 \mu \mathrm{mol} \mathrm{L}{ }^{-1}(n=99)$ corresponding to $60 \%$ air saturation.

In total, the station was visited 11 times during the study period and on 8 occasions one or more of four instrumental tripods was deployed. The tripods were lowered from the RV Calanus or the RV Soel Mara with a buoyant rope and were moored with a surface buoy. A $30-\mathrm{kg}$ weight fixed to the rope was placed 30-50 m from the instruments so that any drag from the surface buoy was not conveyed to the tripods at the sea bed. The respective tripods were deployed for periods of 6-60 h depending on weather conditions, logistical constraints and the type of instrumentation. One of the tripods always carried a conductivity, temperature, depth (CTD) instrument (XR-420, RBR) equipped with an $\mathrm{O}_{2}$ optode (Tengberg et al. 2006; Aanderaa) to monitor physico-chemical parameters in the bottom water.

In total we conducted 7, 6 and 5 successful deployments with a transecting microprofiler, a benthic chamber and the eddy covariance instrument, respectively. In addition, an 
underwater camera system (ocean imaging systems) set in time lapse imaging mode and equipped with strobe light was deployed twice to assess the sediment appearance and the dominant macrofauna in the study area. Sediment recovered by the benthic chamber was used to quantify the benthic fauna community. In addition, sediment recovered by a van Veen grab was used to collect the dominant infauna species (Amphiura filiformis) for more detailed laboratory investigations on sediment oxygenation as induced by fauna activity.

Smaller subsets of data from the current study have previously been presented, with the aim of evaluating (1) implications of benthic boundary layer dynamics for the $\mathrm{O}_{2}$ exchange as derived by eddy covariance (Holtappels et al. 2013) and (2) procedures for assessing in situ friction velocities (Inoue et al. 2011). Here we present the entire reanalysed data set with the aim of evaluating benthic mineralization and nutrient regeneration in these highly bioturbated sediments.

\subsection{Laboratory Investigation of Fauna-Induced $\mathrm{O}_{2}$ Dynamics}

Recovered sediment was submerged in air-flushed bottom water and kept at in situ temperature for 1 month. Hereafter the sediment was carefully transferred to narrow Perspex aquaria $(L \times W \times H: 12 \times 2 \times 12 \mathrm{~cm})$ equipped with $\mathrm{O}_{2}$ quenchable planar optodes (see below). During sediment transfer any observed macrofauna was manually removed while maintaining the overall sediment structure. The sediment-filled aquaria were placed in bottom water kept at in situ temperature and at $100 \%$ air saturation. After 4 weeks, freshly sampled specimens of $A$. filiformis from the study site were introduced to the aquaria, one or two specimen per aquaria. The animals quickly dug into the sediment, and three aquaria with four animals which had positioned themselves along the planar $\mathrm{O}_{2}$ sensor were selected for detailed imaging, one aquarium at the time. Images with the planar optode system were obtained with a frequency of $5 \mathrm{~min}$ for a total of up to $30 \mathrm{~h}$ while the selected aquarium at each occasion was inserted into a larger thermo-regulated tank filled with bottom water from the sampling site. The overlying water was continuously flushed with an air pump to ensure constant temperature and $100 \%$ air saturation.

The applied planar optode system used in the study was similar to previously described systems (Holst et al. 1998; Frederiksen and Glud 2006) and will only be presented briefly. The $11 \times 11 \mathrm{~cm}$ large transparent planar optode was based on an $\mathrm{O}_{2}$ quenchable ruthenium(II) luminophore immobilized in polystyrene and coated onto a transparent polyester support foil. The sensor was interrogated by a fast gateable 12-bit Charged Coupled Device camera (CCD, SensiCam, PCO.de) equipped with a 60-mm Nikon macrolens and a 570nm-longpass filter (UQGoptics.com). Excitation light was delivered from four blue highpower LEDs (LXHL-LR3C, Luxeon.com) equipped with a 470-nm-shortpass filter (UQGoptics.com). The operation of camera and LEDs was synchronized via a custommade PC-controlled trigger box using the software Look@Molli (Holst and Grunwald 2001). The luminescent lifetime was inferred from two well-defined time frames configured by the interactive software. Recorded images were calibrated using the average luminescent lifetime of two areas of the homogenous planar optode that were exposed to known $\mathrm{O}_{2}$ levels (100\% air saturation in the overlying water and $0 \%$ air saturation in deep presumed anoxic layers), using a modified rearranged Stern-Volmer equation (Glud et al. 1996): 


$$
C=\frac{\tau_{0}-\tau}{K_{\mathrm{SV}} \cdot\left(\tau-\alpha \tau_{0}\right)}
$$

where $\tau_{0}$ is the luminescent lifetime in the absence of $\mathrm{O}_{2}, \tau$ is the lifetime in the presence of $\mathrm{O}_{2}$ at a level of $C, K_{\mathrm{SV}}$ is the Stern-Volmer quenching constant, and $\alpha$ is the nonquenchable fraction of the luminescent signal which was experientially determined to be 0.2. All images were recorded in ambient darkness.

To visualize the organization of intact burrow structures in the sediment, one Perspex aquarium $(L \times W \times \mathrm{H}: 16 \times 8 \times 16 \mathrm{~cm})$ with recovered sediment and animals was kept at in situ temperature and was transported to a Toshiba Aquilion medical CT (computeraided tomography) scanner at the local hospital (Lorn \& Island Hospital, Oban, Argyll, UK). The CT scanner was operated with a power setting of $120 \mathrm{kV}$ and $175 \mathrm{~mA}$, and the resolution of the images obtained by the scanner was $0.26 \mathrm{~mm} \times 0.26 \mathrm{~mm} \times 1.00 \mathrm{~mm}$ (or $0.068 \mathrm{~mm}^{-3}$ ). The total scanning procedure took about $1 \mathrm{~s}$. Subsequent image analyses were performed by the freeware ImageJ.

\subsection{In Situ Microprofiling Instrument}

In situ microprofiles of $\mathrm{O}_{2}$ and $\mathrm{NO}_{3}{ }^{-}$were obtained by a previously presented transecting microprofiling instrument (Glud et al. 2009a) that for the respective deployments was equipped with 2-4 Clark-type $\mathrm{O}_{2}$ microelectrodes (Revsbech 1989) and $2 \mathrm{NO}_{3}{ }^{-}$microelectrodes (Revsbech and Glud 2009). During one deployment the instrument was also equipped with two $\mathrm{H}_{2} \mathrm{~S}$ microsensors (Kühl et al. 1998), but no free $\mathrm{H}_{2} \mathrm{~S}$ could be detected in the upper $5 \mathrm{~cm}$ of the sediment. A titanium cylinder containing electronics and the mounted sensors was placed on a sledge that could move a total horizontal distance of $90 \mathrm{~cm}$ in increments of $0.7 \mathrm{~cm}$ obtaining one set of microprofiles at each position. The instrument could therefore obtain numerous profiles during a single deployment (Glud et al. 2009a). However, given the high density of infauna at the present study site, the microsensors were frequently damaged during the initial measurements, and we only obtained a total of 50 intact microprofiles during the 7 deployments. The $\mathrm{O}_{2}$ sensors had a tip diameter of $1-5 \mu \mathrm{m}, 90 \%$ response time $<0.5 \mathrm{~s}$ and stirring sensitivity $<0.5 \%$ (Revsbech 1989; Gundersen et al. 1998), while typical $\mathrm{NO}_{3}{ }^{-}$sensors had an outer diameter of $\sim 150 \mu \mathrm{m}$, a $90 \%$ response time of 1-2 min and were insensitive to stirring (Revsbech and Glud 2009). The sensors responded linearly towards solute concentrations, and the signals were calibrated against known concentrations in the bottom water and low readings in deep sediment layers that were presumed to be free of $\mathrm{O}_{2}$ and $\mathrm{NO}_{3}{ }^{-}$. The $\mathrm{NO}_{3}{ }^{-}$ microsensor is cross-sensitive to $\mathrm{NO}_{2}{ }^{-}$and $\mathrm{N}_{2} \mathrm{O}$, but as the concentration of these solutes generally is well below $1 \mu \mathrm{mol} \mathrm{L}{ }^{-1}$ in marine sediments, such potential interference was ignored (Revsbech and Glud 2009). Microprofiles were measured at a vertical resolution of $0.2 \mathrm{~mm}$, and sensors were kept at each measuring depth for 2 min to ensure that the $\mathrm{NO}_{3}{ }^{-}$ sensors had responded fully before recording the data. The diffusive solute exchange (J) was calculated from Fick's first law of diffusion: $J=-\mathrm{D} d C / \mathrm{d} Z$, where $D$ is the molecular diffusion coefficient and $\mathrm{d} C / \mathrm{d} Z$ is the slope of the linear concentration gradient. When possible, we applied the concentration gradient of the diffusive boundary layer (DBL) and the molecular diffusion coefficient at in situ temperature and salinity $\left(D_{0}=1.6310^{-5} \mathrm{~cm} \mathrm{~s}^{-1}\right.$ ) (Rasmussen and Jørgensen 1992). However, in some instances the spatial resolutions in the DBL was insufficient for applying this procedure and in other instances we wanted to calculate fluxes below the sediment surface. For instance, this was the case when deriving the nitrification rate in the oxic surface layer, where the upward and 
downward flux from the concentration peak was calculated, the first representing an efflux to the overlying water and the latter sustaining underlying denitrification (Glud et al. 2009b). In those instances, we applied the concentration gradient in the sediment and the tortuosity corrected molecular diffusion coefficient as derived from $D_{s}=D_{0} \varphi^{(m-1)}$, where $\varphi$ is the porosity and $m$ was a sediment constant assumed to be 3 (Ullmann and Aller 1982). Both procedures were tested on a few profiles which provided very similar results for the diffusive $\mathrm{O}_{2}$ exchange across the sediment water interface (not shown).

\subsection{In Situ Chamber Incubations}

To quantify the total benthic exchange rates of $\mathrm{O}_{2}, \mathrm{~N}_{2}$ and nutrients, we deployed the benthic chamber lander Elinor (Glud et al. 1995) which is based on the design of the BECIlander (Jahnke and Christensen 1989). The squared chamber enclosed $\sim 900 \mathrm{~cm}^{2}$ of sediment with an overlying water column of $10-15 \mathrm{~cm}$. As the tripod settled at the seabed, the chamber was inserted in the sediment and after $1 \mathrm{~h}$ the incubation was initiated by lid closure. During incubations a central cross-bar stirred the overlying water at 10 RPM (revolutions per minutes) which ensured a well-mixed overlying water column and an average diffusive boundary layer (DBL) thickness on the order of $\sim 0.5 \mathrm{~mm}$ (Glud et al. 1995). During incubations, the $\mathrm{O}_{2}$ concentration of the enclosed water was measured every 30 min using a commercially available $\mathrm{O}_{2}$ optode (AADI 4835, Andreaa) (Tengberg et al. 2006, Andreaa; AADI 4835), and data were internally stored. Additionally, 5-8 water samples were taken from the enclosed water at regular intervals by spring-loaded, $50-\mathrm{mL}$ glass syringes that were triggered by a motorized spindle controlled by the preprogrammed electronics (Glud et al. 1995). The sampled water was replaced via a 3-mm (inner diameter), 50-cm-long, coiled tube connecting the chamber to the outside water. At the end of the incubation, a scoop closed beneath the chamber and the incubated sediment core was recovered with the tripod (Jahnke and Christensen 1989). Upon recovery, each of the $50 \mathrm{~mL}$ water samples were divided into three subsamples and preserved for subsequent concentration measurements of dissolved inorganic carbon (DIC), $\mathrm{N}_{2}$ and nutrients $\left(\mathrm{NH}_{4}{ }^{+}\right.$, $\left.\mathrm{NO}_{3}{ }^{-}, \mathrm{PO}_{4}{ }^{3-}, \mathrm{DSi}\right)$. For DIC, $12 \mathrm{~mL}$ of subsample was stored in gastight Excitainers (Labco, UK) spiked with $200 \mu \mathrm{L}$ saturated $\mathrm{HgCl}_{2}$ until analysis on a coulometer (CM5012 UIC Coulometrics; precision $\pm 2 \mu \mathrm{mol} \mathrm{L}^{-1}$ ) (Johnson et al. 1987). Samples for $\mathrm{N}_{2}-\mathrm{Ar}$ measurements were stored at $15^{\circ} \mathrm{C}$ in submerged $7-\mathrm{mL}$ glass stoppered vials with $100 \mu \mathrm{L}$ saturated $\mathrm{HgCl}_{2}$ until analysis on membrane inlet mass spectrometer (Balzers QMS422; precision for $\mathrm{N}_{2}$ determination $\pm 0.5 \mu \mathrm{mol} \mathrm{L}^{-1}$ ) (Eyre et al. 2002). For nutrients, $25 \mathrm{~mL}$ of water was filtered through $25-\mathrm{mm}, 0.45-\mu \mathrm{m}$-pore-size filters (Whatman GF/F) and either frozen at $-18{ }^{\circ} \mathrm{C}$ (for $\mathrm{NH}_{4}{ }^{+}, \mathrm{NO}_{3}{ }^{-}, \mathrm{PO}_{4}{ }^{3-}$ ) or stored at $4{ }^{\circ} \mathrm{C}$ (for DSi) until analyses. The samples were analysed within 1 week after sampling using a LACHAT QuikChem 8500 Flow Injection AutoAnalyser (LaChat Instruments) and corrected for blanks (Sargasso Seawater from OSIL). The precisions as assessed by replicate measurements of standards in the relevant measuring range $(n=6)$ were $0.03,0.07,0.01$ and $0.2 \mu \mathrm{mol} \mathrm{L}{ }^{-1}$ for $\mathrm{NH}_{4}{ }^{+}$, $\mathrm{NO}_{3}{ }^{-}, \mathrm{PO}_{4}{ }^{3-}$ and $\mathrm{DSi}$, respectively. The total exchange rate of the respective solutes was quantified assuming linear development in concentration changes during incubations and by accounting for the enclosed volume of water.

\subsection{Eddy Covariance Measurements}

The applied aquatic eddy covariance (AEC) system was similar to the one described by Berg and Huettel (2008). The main components consisted of an acoustic Doppler 
velocimeter (ADV, Vector, Nortek) and an $\mathrm{O}_{2}$ microelectrode with the same measuring characteristics as described above. The $\mathrm{O}_{2}$ microsensor signal was relayed to the ADV via a submersible amplifier (McGinnis et al. 2011). The vertically aligned ADV recorded the longitudinal, traverse and vertical velocity components along with the output from the $\mathrm{O}_{2}$ microsensor at a frequency of $32 \mathrm{~Hz}$, which allowed full resolution of the current-driven turbulence transporting $\mathrm{O}_{2}$ to the seafloor. The data were recorded in 15-min-long bursts consisting of $14.5 \mathrm{~min}$ of continuous sampling followed by 0.5 -min sleep period with no data collection. The ADV sampling volume $(1.5 \times 1.5 \mathrm{~cm})$ was located $\sim 10-15 \mathrm{~cm}$ above the seabed surface, and the $\mathrm{O}_{2}$ microelectode tip was positioned a few mm outside the sampling volume of the ADV to ensure uncompromised velocity measurements. Prior to deployment, the AEC $\mathrm{O}_{2}$ microsensors were left to polarize for a minimum of $\sim 12 \mathrm{~h}$ to minimize sensor drift and their "zero readings" were measured by dipping the sensor tips in a sodium dithionite solution. Before flux extraction, each sensor was calibrated against the known bottom water concentration of $\mathrm{O}_{2}$ (see above) and its zero reading.

$\mathrm{O}_{2}$ exchange rates, one for each 15-min burst, were extracted from the raw EC data set using the software package EddyFlux version 3.00 (P. Berg unpubl.). In short, the raw EC data were averaged down to $8 \mathrm{~Hz}$ which provided sufficient resolution to describe the entire frequency spectrum carrying the flux signal. Spectral analysis was applied to selected data sequences to validate this assumption. Abnormalities in the EC data record, usually caused by debris colliding with or attaching to the $\mathrm{O}_{2}$ sensor, were then removed as described by Lorrai et al. (2010), Hume et al. (2011) and Berg et al. (2013). In total $\sim 18 \%$ of the data were discarded by this procedure. To compensate for any sensor tilt, the velocity field for each burst was rotated which nullified the transverse and vertical mean velocities. To compensate for the limited response time of the $\mathrm{O}_{2}$ microelectrode $(<0.5 \mathrm{~s})$ and the physical separation between the $\mathrm{O}_{2}$ sensor tip and the centre of ADV's measurement volume, a time lag correction was applied to each burst. This was done by repeating the flux calculation for each burst while shifting the $8-\mathrm{Hz}$ concentration data in $1 / 8 \mathrm{~s}$ increments until the numerically largest flux was found (McGinnis et al. 2008; Lorrai et al. 2010). The identified time shifts, one for each burst, varied with the mean current velocity and its direction, but averaged over all deployments, this correction increased the flux by $25 \%$ (McGinnis et al. 2008; Lorrai et al. 2010; Donis et al. 2015). The $\mathrm{O}_{2}$ fluxes, in mmol $\mathrm{m}^{-2} \mathrm{day}^{-1}$, were then extracted from the vertical ADV velocity $(w)$ and the measured $\mathrm{O}_{2}$ concentrations $(C)$ as the covariance $w^{\prime} C^{\prime}$, where the fluctuation components, $w^{\prime}$ and $C^{\prime}$, are deviations from a least-squares linear fit to the data in each burst (Lee et al. 2004; Berg et al. 2009). The variation in the derived EOE was quantified by both the SD and standard error of the burst values during the respective deployments.

Recently, it has been shown that stirring sensitivities of $\mathrm{O}_{2}$ microelectrodes can confound the eddy-derived $\mathrm{O}_{2}$ exchange EOE and provide an artificial flux contribution (Holtappels et al. 2015). Provided the sensor characteristics and measuring conditions the maximum effect was assessed by the procedure described in Berg et al. (2015) and amounted to $8 \%$ of the measured flux. However, as the applied sensors will not express maximum stirring sensitivity from all current directions (Holtappels et al. 2015) the average effect for the respective deployments must have been considerably less. In the following, we have therefore ignored this minor offset of the derived EOE.

\subsection{Basic Sediment Characteristics and Quantification of Macrofauna}

Sediment porosity and organic content were determined in two sediment cores that were subsampled from a box corer that had been recovered with a clear overlying water phase. 
The cores were sectioned into $1-\mathrm{cm}$ slices down to $10 \mathrm{~cm}$ depth, and porosity was quantified from the weight loss after drying for $24 \mathrm{~h}$ at $105{ }^{\circ} \mathrm{C}$ and the wet density. The organic content of the dried sediment was determined as the relative weight loss upon ignition after $24 \mathrm{~h}$ at $450{ }^{\circ} \mathrm{C}$ without an acidification step. However, relevant sedimentary carbonates remain stable at this temperature and should not confound the assessment of the organic content (Krom and Berner 1983). For quantification of macrofauna, four intact sediment cores $\left(900 \mathrm{~cm}^{2}\right)$ that were recovered by the benthic chamber lander were sieved through a 1 -mm mesh, and animals were collected and stored in $70 \%$ ethanol for subsequent taxonomic determination.

\section{Results}

\subsection{Basic Sediment Characteristics and Fauna-Induced Oxygenation}

The cohesive sediment consisted of silty mud, and the surface appeared well mixed as the upper $5 \mathrm{~cm}$ exhibited no distinct vertical profiles in porosity or organic content (not shown). On average, the surface sediment had a porosity of $0.90 \pm 0.05(n=10)$, while the dry organic content was $12.6 \pm 1.2 \%(n=10)$. This is a relatively high value for coastal sediments in general, but it aligns well with previous measurements in Loch Etive and other Lochs in the region (Overnell et al. 1996). Below the 5-cm surface layer, both porosity and organic content tended to decline to minimum values of 0.88 and $10.5 \%$ at the deepest sampling point of $10 \mathrm{~cm}$ (not shown). The sediment hosted abundant macrofauna with a total wet-weight biomass of $272 \pm 84 \mathrm{~g} \mathrm{~m}^{-2}(n=4)$ as assessed from intact sediment cores of the benthic chamber. The faunal abundance was clearly dominated by ophiuroids $\left(1070 \pm 280 \mathrm{~m}^{-2}\right)$, followed by polychaetes $\left(370 \pm 223 \mathrm{~m}^{-2}\right)$ and small bivalves $\left(330 \pm 16 \mathrm{~m}^{-2}\right)$. These taxonomic groups accounted for $>95 \%$ of the abundance, and the single most abundant species was A. filiformis accounting for $820 \pm 139 \mathrm{~m}^{-2}$. In situ time lapse images of the sediment surface clearly revealed the dense coverage of arms of $A$. filiformis extending from the sediment and filter feeding in the bottom water (Fig. 2a). A three-dimensional CT scan of an intact sediment block showed how the sediment was interwoven by burrows of A. filiformis. Typically, the animals were sitting slanted in a central cavity with 2 or 3 arms forming open channels to the sediment surface (Fig. 2b). We only scanned one intact sediment block, and for this sample, the density of $A$. Filiformis burrows amounted to $1503 \mathrm{~m}^{-2}$ and the overall burrow volume in the upper $10 \mathrm{~cm}$ was $4824 \mathrm{~cm}^{3} \mathrm{~m}^{-2}$. This equates to $4.8 \%$ of the sediment volume of the upper $10 \mathrm{~cm}$. The $\mathrm{O}_{2}$ images of intact burrow systems documented how filter feeding animals drew oxygenated water down along one arm and into the central cavity while $\mathrm{O}_{2}$ depleted, and on some occasions even anoxic, water left through another outlet (Fig. 2d, f). Typically, 2-3 of the five arms were used for irrigation, while the remaining arms moved around in (or below) the central cavity. Two full 25-h-long movies showing the $\mathrm{O}_{2}$ dynamics and animal activity associated with an inhabited burrow can be seen in the supplementary material. Generally, the irrigation was very dynamic and in most cases without any distinct rhythm. This resulted in a highly variable $\mathrm{O}_{2}$ concentration within the burrow system and the central cavity (Fig. 2d-f). However, while the arm channels frequently experienced complete anoxia, the central cavity generally remained oxic with values ranging between 1 and $50 \mu \mathrm{mol} \mathrm{L}^{-1}$ (Fig. $2 \mathrm{~g}$ ). Addition of food particles (Interpet Liquifry Marine) to the aquaria clearly stimulated the ventilation activity of the 

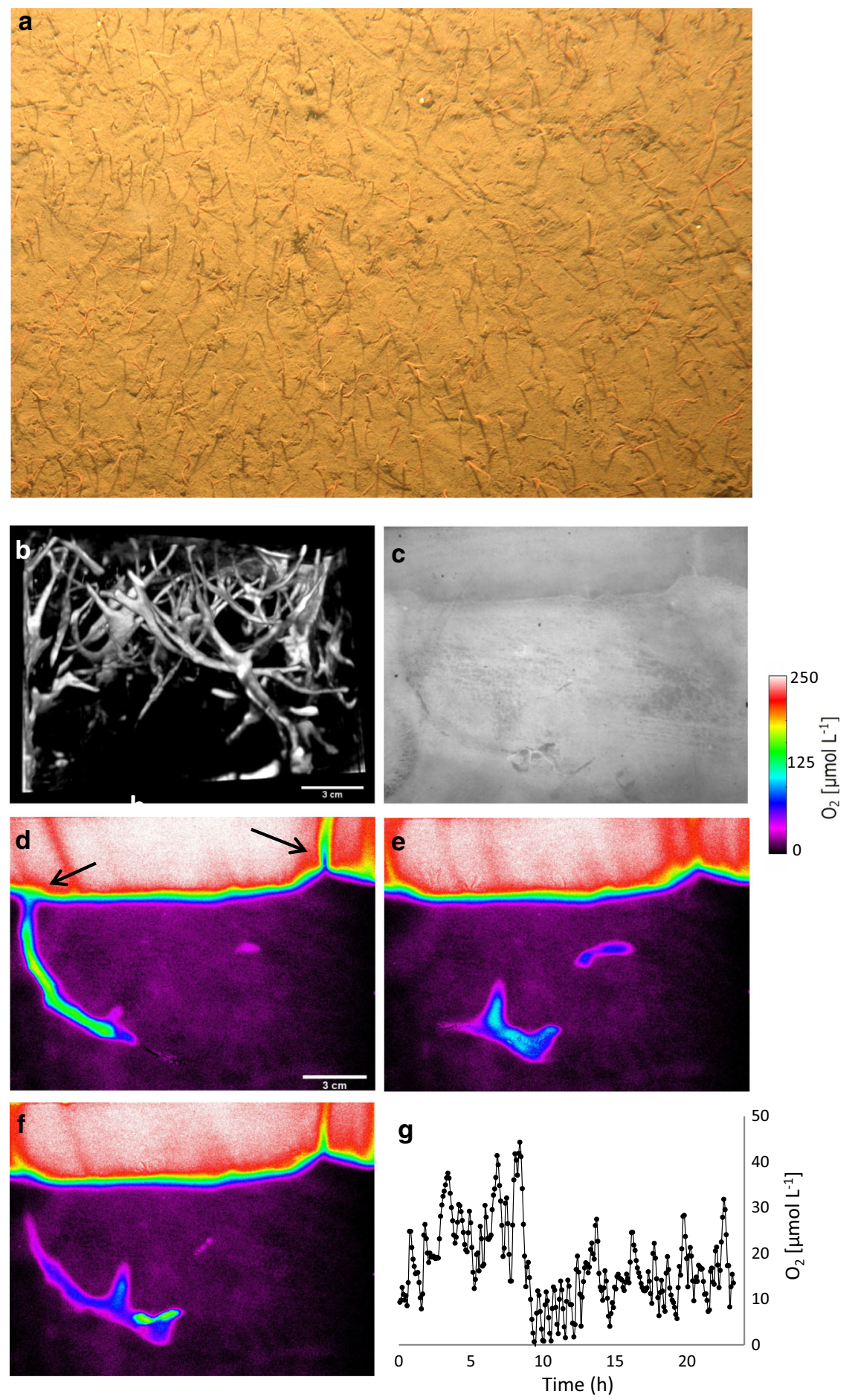
TFig. 2 a One typical in situ image $(89 \times 63 \mathrm{~cm})$ of the seabed at the study site showing a high density of arms from $A$. filiformis that are extending from the sediment surface. b A 3D, CT scan of burrow structures in an intact block of sediment containing actively ventilating brittle stars at natural densities. $\mathbf{c}$ One typical black-and-white image selected from a 30-h time series of images at the sediment water interface obtained at a frequency of $5 \mathrm{~min}$. The image was obtained through a transparent $\mathrm{O}_{2}$ optode, and the central cavity with the disc and arms extending to the left and right from a single specimen of A. filiformis can be observed. df depict three selected images of the $\mathrm{O}_{2}$ distribution within and around the ventilated burrow system. One arm is used to channel air-saturated water into the central cavity while $\mathrm{O}_{2}$-depleted water is exhaled to the right (indicated by arrows). $\mathbf{g}$ The $\mathrm{O}_{2}$ concentration within the central cavity as extracted from $25 \mathrm{~h}$ of continuous $\mathrm{O}_{2}$ images. The full movie on animal activity in black-and-white and the concurrent $\mathrm{O}_{2}$ dynamics is available in the supplementary material

animals (not shown). A. filiformis therefore irrigated the upper $\sim 10 \mathrm{~cm}$ of the sediment with bottom water leading to a highly dynamic oxic environment in arm channels, the cavities and the surrounding sediment. Both the laboratory observations and the in situ time lapse images of the surface sediment (Fig. 2a) suggested that the animals and their burrow systems were stationary.

\subsection{In Situ Microprofile Measurements}

During the seven deployments of the profiling instrument, we successfully obtained $36 \mathrm{O}_{2}$ and $14 \mathrm{NO}_{3}{ }^{-}$microprofiles (and a few $\mathrm{H}_{2} \mathrm{~S}$ microprofiles documenting that the upper $5 \mathrm{~cm}$ of the sediment was $\mathrm{H}_{2} \mathrm{~S}$-free). Most microsensors broke during profiling, presumably as a consequence of the high density of infauna. On average $\sim 50 \%$ of the microprofiles were visually affected by burrow structures and irrigation, as reflected by subsurface concentration peaks and irregular signals (Fig. 3). In most cases these anomalies were encountered in the deeper otherwise anoxic sediment layers well below the oxygenated surface layer (Fig. 3). Only including the apparently undisturbed surface layer, the microprofiles still exhibited an extensive small-scale variations (Fig. 3), and the average $\mathrm{O}_{2}$ penetration depth along the sediment surface was $4.0 \pm 1.3 \mathrm{~mm}(n=36)$. Only including $\mathrm{O}_{2}$ measurements that at the surface appeared unaffected by animal activity provided an average diffusive $\mathrm{O}_{2}$ exchange (DOE) of $-7.5 \pm 2.3 \mathrm{mmol} \mathrm{m}^{-2}$ day $^{-1}(n=26)$. The measured $\mathrm{NO}_{3}{ }^{-}$microprofiles also exhibited an extensive small-scale variation; while most profiles had clear nitrification peaks at the sediment surface and a relatively deep $\mathrm{NO}_{3}{ }^{-}$penetration (Fig. 3e, f, h), other profiles reflected a fast exhaustion of $\mathrm{NO}_{3}{ }^{-}$just below the sediment surface (Fig. 3g). Consequently, $\mathrm{NO}_{3}{ }^{-}$penetration depth at the apparently undisturbed sediment-water interface varied by a factor of $\sim 5$, but on average amounted to $6.2 \pm 3.5 \mathrm{~mm}(n=14)$. Correspondingly, the diffusive net exchange of nitrate at the sediment water interface varied extensively, but on average the exchange rate across the sediment water interface amounted to $0.12 \pm 0.40 \mathrm{mmol} \mathrm{m}^{-2}$ day ${ }^{-1}(n=14)$. As for $\mathrm{O}_{2}$, the irrigation by $A$. filiformis clearly infused $\mathrm{NO}_{3}{ }^{-}$enriched water deep into the burrow structure well below the primary interface, and the irrigation enhanced the overall net exchange of solutes (Fig. 3).

\subsection{Benthic Chamber Incubations}

Whereas the microprofiles resolved an extensive small-scale variation in distribution and diffusive exchange rates of $\mathrm{O}_{2}$ and $\mathrm{NO}_{3}{ }^{-}$, the benthic chamber incubations provide an integrated total net-exchange rate across areas of $\sim 900 \mathrm{~cm}^{2}$. In most cases, the concentration changes within the enclosed water volume could be reasonably well approached by 


\section{Oxygen $(\mu \mathrm{mol} \mathrm{L}-1)$}

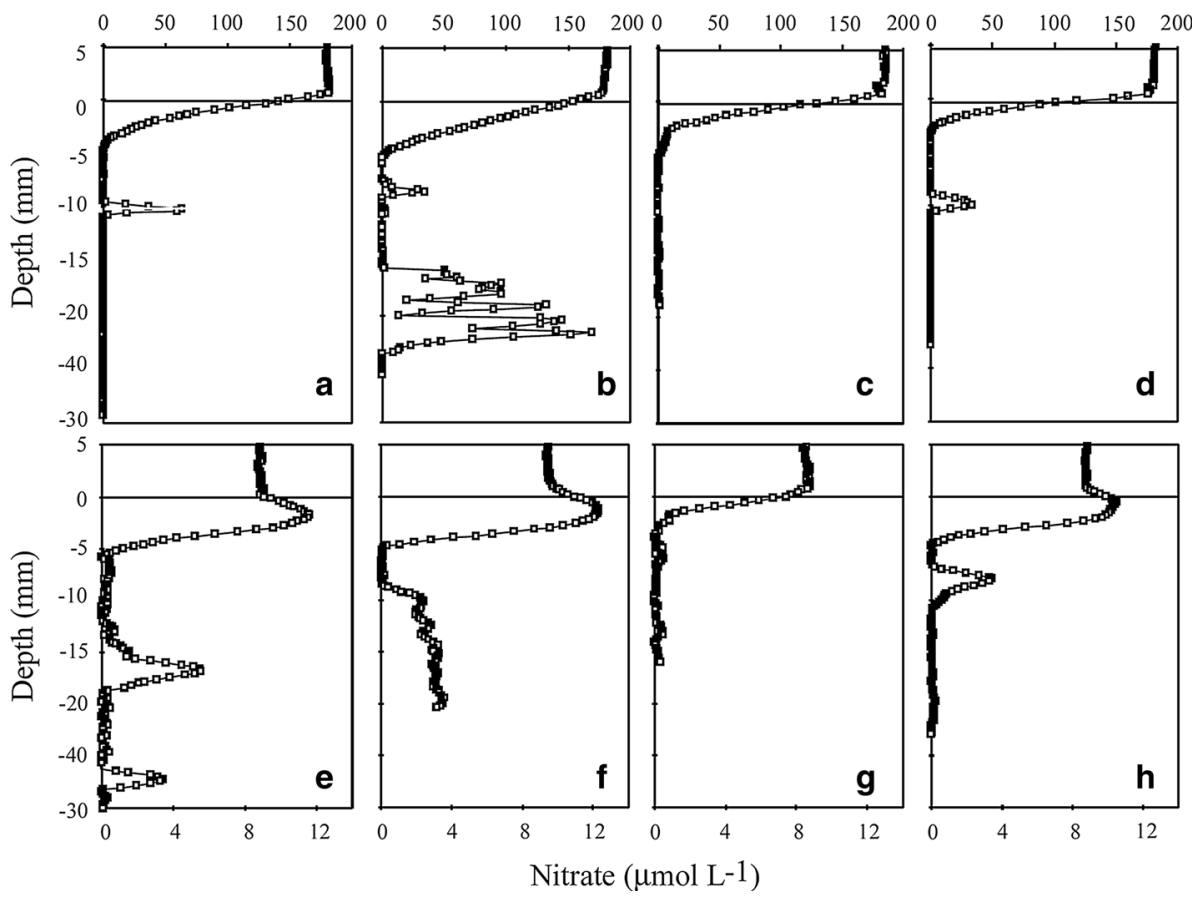

Fig. 3 a-d Typical $\mathrm{O}_{2}$ microprofiles as measured by the transecting profiling instrument. The estimated sediment surface as reflected by a slight shift in the concentration slope is indicated by the thin horizontal line. Many profiles showed clear signs of irrigation with $\mathrm{O}_{2}$ peaks deep within the sediment presumably penetrating irrigated burrows (a, d) or larger cavities (b). e, f depict typical microprofiles of $\mathrm{NO}_{3}{ }^{-}$ distribution at the sediment-water interface. Some profiles reveal intense $\mathrm{NO}_{3}{ }^{-}$production (nitrification) at the oxic surface $(\mathbf{e}-\mathbf{h})$. As for $\mathrm{O}_{2}$, irrigation clearly transported $\mathrm{NO}_{3}{ }^{-}$deep into burrows $(\mathbf{e}, \mathbf{h})$ or larger cavities (f) of the sediment

a simple linear relation (Fig. 4). In total we conducted 6 successful chamber deployments, but DSi analyses were only carried out on the last two deployments. Overall total $\mathrm{O}_{2}$ exchange (TOE) rates amounted to $-14.9 \pm 2.5 \mathrm{mmol} \mathrm{m}^{-2}$ day $^{-1}$, while the DIC release amounted to $15.5 \pm 3.4$ (Table 1) providing an average sediment respiratory quotient (RQ) of $1.03 \pm 0.11$. The sediment consistently effluxed $\mathrm{NH}_{4}{ }^{+}, \mathrm{PO}_{4}{ }^{3-}$ and $\mathrm{DSi}$, while there was a net uptake of $\mathrm{NO}_{3}{ }^{-}$that scaled with the efflux of $\mathrm{NH}_{4}{ }^{+}$(Table 1). On four occasions we managed to obtain reliable samples for $\mathrm{N}_{2}$ determination (Fig. 5), and they consistently documented a net efflux of $\mathrm{N}_{2}$ (Table 1).

\subsection{Benthic $\mathrm{O}_{2}$ Consumption as Quantified by Eddy Covariance}

The five deployments of our eddy covariance instrument provided a total of $119 \mathrm{~h}$ of successful measurements. While the benthic chamber incubations integrate the microscale variability resolved by the microprofiles, the eddy $\mathrm{O}_{2}$ exchange (EOE) non-invasively resolves the net $\mathrm{O}_{2}$ exchange across a large (10-100 $\mathrm{m}^{2}$ ), area upstream from the measuring point. The approach therefore overcomes potential mesoscale variations in $\mathrm{O}_{2}$ 
Fig. 4 Changes in $\mathrm{O}_{2}$, DIC and nutrient concentrations within a single in situ chamber incubation conducted at 5 November 2008 at $65 \mathrm{~m}$ water depth (deployment 6). Flux rates were derived from linear approximations of the concentration changes and by accounting for the enclosed volume of water
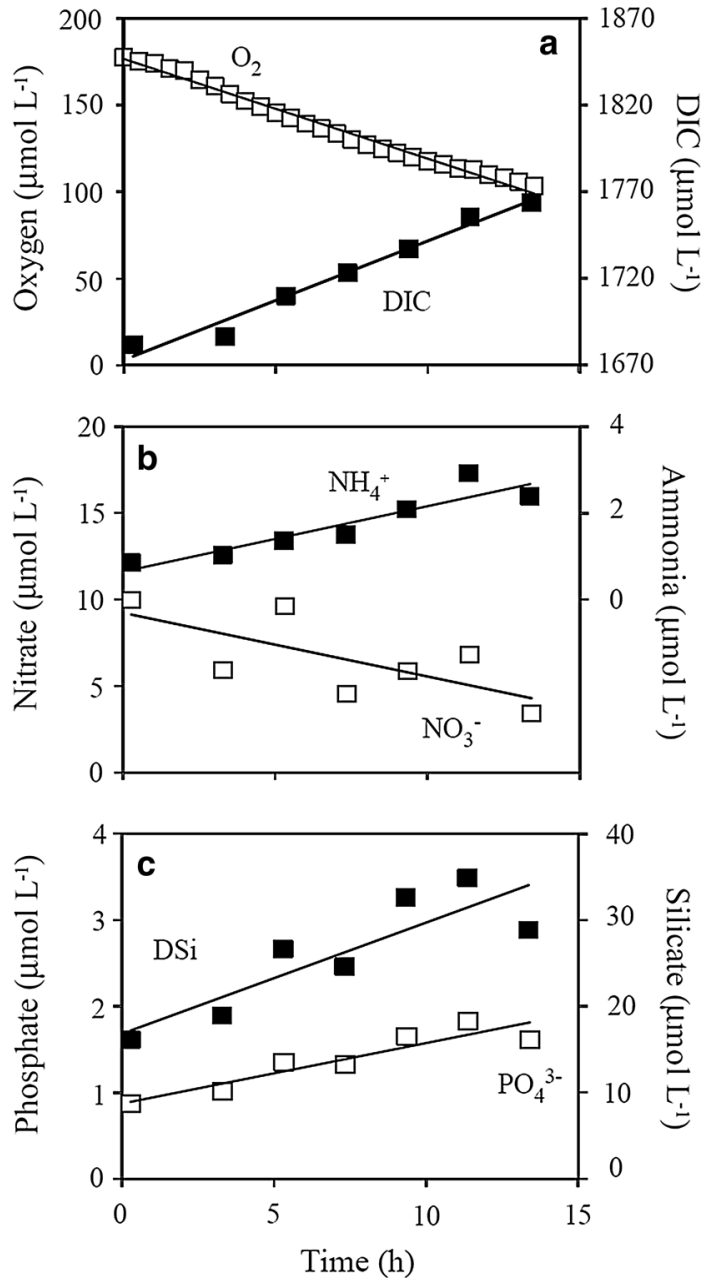

consumption at the seabed. The area included in the EOE measurement changes with the current direction. However, in the present study there was no apparent relation between current direction and the size of the resolved fluxes, indicating a homogenous average $\mathrm{O}_{2}$ consumption at the scale of the footprint size. In situ images of the sea floor in the area also appeared similar.

The measuring approach resolved the turbulent-driven solute exchange well above the viscous sublayer, and as expected, the time series exhibited an extensive burst to burst (15min periods) variation (Fig. 6). However, overall burst values tended to be related to the ambient flow velocities with increasing $\mathrm{O}_{2}$ exchange during periods of elevated horizontal flow rates driven by tides (Fig. 6). The average EOE for the respective five deployments varied between 9.5 and $15.0 \mathrm{mmol} \mathrm{m}{ }^{-2}$ day $^{-1}$ with an overall weighted average for the five deployments of $13.1 \pm 9.0 \mathrm{mmol} \mathrm{m}^{-2}$ day $^{-1}(\mathrm{SE}=0.5 ; n=493)$. 


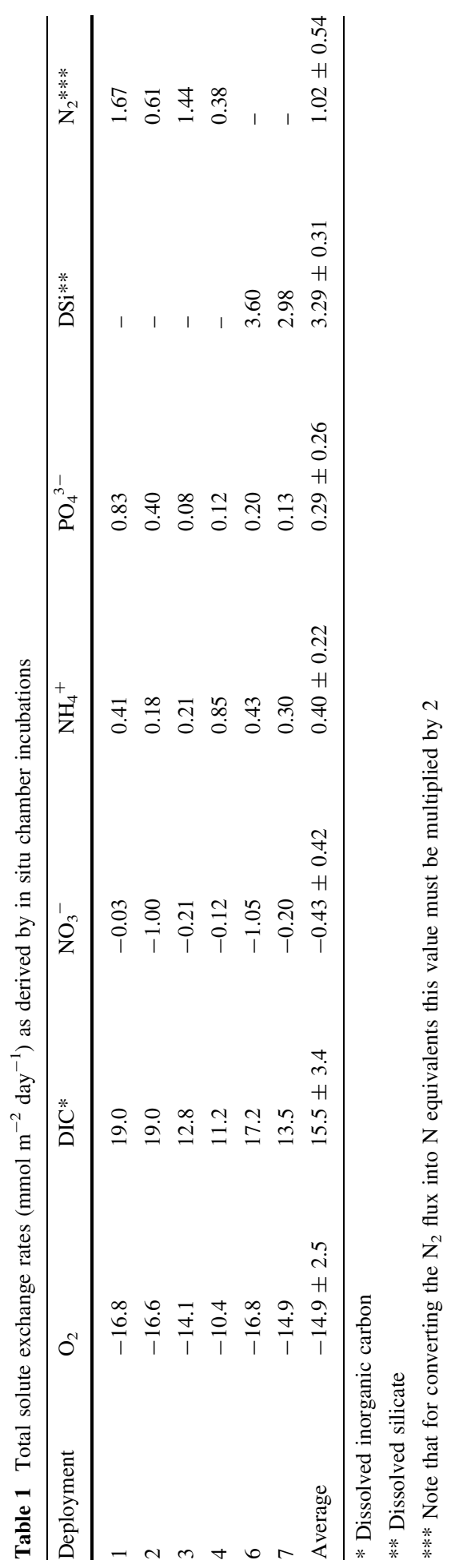


Fig. 5 Changes in $\mathrm{N}_{2}$ within four separate in situ chamber incubations as derived from overall changes in the measured $\mathrm{N}_{2}$-Ar ratio. Samples containing small bubbles after sampling or storage were discarded. Flux rates were derived from linear approximations of the concentration changes accounting for the enclosed volume of water

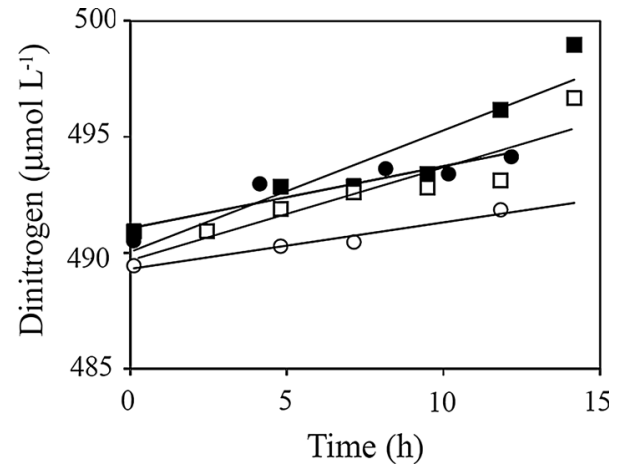

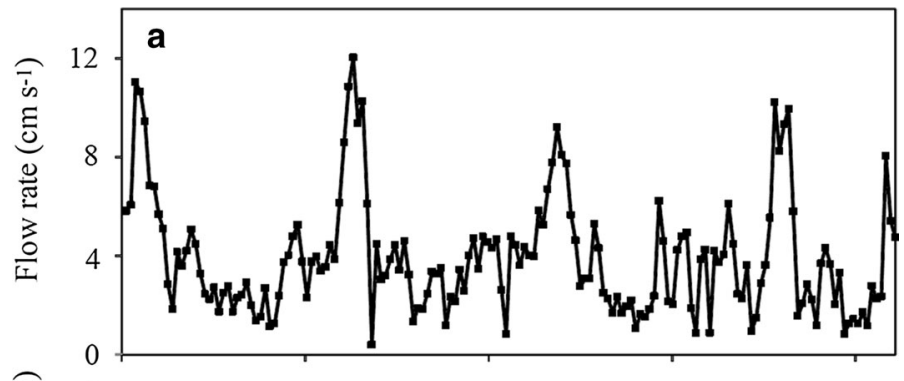

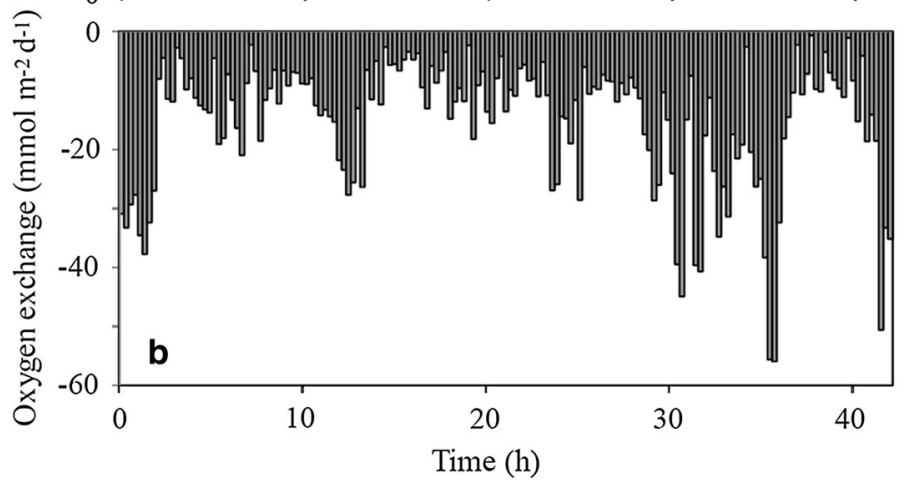

Fig. 6 a Flow rates as derived by the horizontal flow components measured by the ADV of the eddy tripod during a 42-h-long deployment. Values are averages of $14.5 \mathrm{~min}$ of recording. b The concurrent $\mathrm{O}_{2}$ exchange rates as derived by eddy covariance in bursts of $14.5 \mathrm{~min}$. The example represents a deployment from 5 to 6 November 2008 at $68 \mathrm{~m}$, and a parallel data set from 7 to 10 November 2008 at $55 \mathrm{~m}$ has been presented previously (Holtappels et al. 2013)

\section{Discussion}

\subsection{Benthic $\mathrm{O}_{2}$ Uptake as Quantified by Three Different In Situ Approaches}

We applied three in situ approaches to quantify benthic $\mathrm{O}_{2}$ consumption during a total of 18 deployments at an average water depth of $\sim 65 \mathrm{~m}$ in Airds Bay, Loch Etive. The average $\mathrm{O}_{2}$ exchange rates resolved by the chamber incubations and the eddy covariance approach were similar (Fig. 7). This provides confidence in both measuring approaches. It 


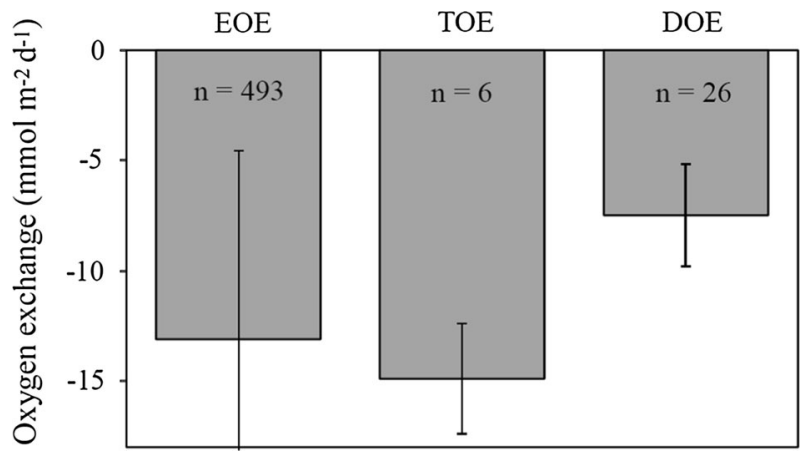

Fig. 7 Benthic $\mathrm{O}_{2}$ exchange as resolved by three different in situ approaches. The error bars represent the standard deviation (For EOE the SE amounted to $0.5 \mathrm{mmol} \mathrm{m}^{-2}$ day $^{-1}$ )

also implies that the chamber incubations-on average-captured the relevant spatial variability and imposed hydrodynamics and a DBL thickness that maintain a near-natural solute exchange of the targeted sediments during incubations. A recent compilation of concurrent eddy deployments and chamber incubations also concluded that while TOE and EOE provide different rates in complex benthic habitats like merl beds, reefs, seagrass meadows and permeable sand-presumably due to the invasive approach of chamber incubations-values obtained in cohesive mud without conspicuous megafauna are generally similar (Attard et al. 2015 and references therein). This is further validated by the very extensive data set of the current study despite being performed in sediments with a high infauna biomass and irrigation activity.

The non-invasive EOE measurements exhibited a flow-dependent $\mathrm{O}_{2}$ exchange rate. This is attributed partly to the principle of the measuring technique and is partly coursed by actual sediment responses. The eddy covariance approach monitors conditions at some distance from the seabed, typically $10-15 \mathrm{~cm}$, and increasing flow rates will lead to changes in the flow and the $\mathrm{O}_{2}$ concentration profile through the benthic boundary layer (BBL). Increasing flow will enhance downward mixing and the $\mathrm{O}_{2}$ concentration in the BBL and inducing a transient storage of $\mathrm{O}_{2}$ in the water volume below the sensors (Holtappels et al. 2013). Therefore, EOE will transiently increase with increasing flow rates as induced by the tidal forcing, and correspondingly decreasing flow rates will lead to decreasing EOE values. However, the overall long-term average value of EOE as measured over a complete tidal cycle will remain unaffected, but the EOE will exhibit variations reflecting this dynamics in the BBL. Similarly, inflow of $\mathrm{O}_{2}$-enriched (or depleted) water will lead to a transient increase (or decrease) in the EOE value that solely is related to equilibration in the BBL. However, $\mathrm{O}_{2}$ concentration in the bottom water in Airds Bay remained relatively constant during the entire study period. Using data from a different deployment in Airds Bay, than the one depicted in Fig. 6, the effect of non-steady-state distribution of $\mathrm{O}_{2}$ in $\mathrm{BBL}$ for EOE has previously been evaluated in detail (Holtappels et al. 2013). Here it was concluded that this effect indeed could explain some of the observed flow dependence of the EOE, but that other factors as well must have contributed to the observed dynamic in EOE (Holtappels et al. 2013).

Increasing flow rates have been shown to enhance the passive flushing of burrows in the sea bed (Stieglizz et al. 2000; Munksby et al. 2002). Given the extensive volume of burrows containing $\mathrm{O}_{2}$-depleted water, enhanced flushing as driven by increasing ambient 
flow rates could have contributed to the observation of flow-dependent $\mathrm{O}_{2}$ exchange. Also, A. filiformis can shift between deposit and suspension feeding (Woodley 1975) and increasing ambient flow has been shown to enhance their suspension feeding (Loo et al. 1996). It is therefore likely that changing ambient flow rates affected the in situ feeding activity and the feeding behaviour of $A$. filiformis and therefore stimulated the net uptake of $\mathrm{O}_{2}$. We tried to evaluate this from the in situ time lapse images, but given the image quality, it was difficult to assess a pattern in the feeding activity. Furthermore, it has also been demonstrated that increasing flow rates will compress the thickness of the diffusive boundary layer, which again will lead to a transient increase in the DOE (Jørgensen and Des Marais 1992; Glud et al. 2007). Assuming depth-independent $\mathrm{O}_{2}$ consumption rates in the sediment, the DOE following complete elimination of the DBL will increase by a factor of $\left(C_{w} / C_{0}\right)^{0.5}$, where $C_{w}$ and $C_{0}$ are the $\mathrm{O}_{2}$ concentrations in the mixed water phase and at the sediment surface, respectively (Boudreau and Guinasso 1982). Using the $\mathrm{O}_{2}$ microprofiles measured in Airds Bay, the value equates to a maximum of $30 \%$. The flowdependent benthic $\mathrm{O}_{2}$ uptake as resolved by the non-invasive EOE measurements can therefore be attributed to a combination of several effects. The presented data document that if detailed and careful data analyses are undertaken, the eddy covariance approach can provide high-quality measurements of benthic $\mathrm{O}_{2}$ exchange. But it is also clear that to obtain reliable average values, deployments need to be long term capturing the natural variability and the stochastic nature of turbulent-driven solute exchange.

As expected, the DOE was significantly lower than the TOE and EOE (Fig. 7. The difference between DOE and TOE is frequently used as a measure of the fauna-mediated $\mathrm{O}_{2}$ exchange (FOE), and for coastal settings, FOE typically accounts for $\sim 40-50 \%$ of the TOE (Forster et al. 1999; Archer and Devol 1992; Jahnke 2001; Glud et al. 2003; Berelson et al. 2013). The FOE of Airds Bay is estimated to equal $7.4 \mathrm{mmol} \mathrm{m}^{-2} \mathrm{day}^{-1}$ (or 5.6 if we scale to the average EOE) being equivalent to $\sim 50 \%$ of the TOE and reflect the relative high biomass and irrigation activity of the infauna. A recent pulse chase experiment with ${ }^{13} \mathrm{C}$-labelled phytodetritus added to a series of sediment cores recovered from Airds Bay (water depth $70 \mathrm{~m}$ ), identified ophiuroids as key players for processing the supplied material (Woulds et al. 2016). While $\sim 35 \%$ of the processed material was respired $\sim 60 \%$ was taken up by ophiuroids over the 6-day-long incubation. This highlights the importance of the infauna for the initial processing of settled organic material. A very detailed laboratory investigation has previously assessed the importance of A. filiformis for benthic $\mathrm{O}_{2}$ dynamics in coastal sediments (Vopel et al. 2003). The authors conducted the experiments in sediment with an average $\mathrm{O}_{2}$ penetration of $4.0 \mathrm{~mm}$ and a DOU of $8.6 \mathrm{mmol} \mathrm{m}^{-2}$ day $^{-1}$, both values being very similar to our in situ measurements in Airds Bay. The respiration rate of adult individuals was measured to be $191 \mathrm{nmol} \mathrm{O}_{2} \mathrm{~h}^{-1}$, while microcosm incubation assessed the burrow-specific $\mathrm{O}_{2}$ consumption rate to be $391 \mathrm{nmol}$ $\mathrm{O}_{2} \mathrm{~h}^{-1}$ (Vopel et al. 2003). Scaling this to the average abundance of A. filiformis encountered in Airds Bay $\left(820 \pm 139 \mathrm{~m}^{-2}\right)$, these animals would be responsible for an $\mathrm{O}_{2}$ uptake in the order of $11.5 \mathrm{mmol} \mathrm{m}^{-2} \mathrm{day}^{-1}$. This is somewhat higher than our total estimate for FOE $\left(7.4 \mathrm{mmol} \mathrm{m}^{-2} \mathrm{day}^{-1}\right)$. However, considering that the laboratory experiments were performed in normoxic water that was $4{ }^{\circ} \mathrm{C}$ warmer than the current in situ settings and the potential stress associated with laboratory conditions, the values agree within expected bounds.

The combined data show how the infauna, dominated by A. filiformis, markedly enhanced the benthic $\mathrm{O}_{2}$ uptake mainly through the dynamic irrigation of numerous complex burrows in the surface sediment. This induced highly dynamic redox conditions in 
the burrow environment, which must have significant implications for benthic carbon mineralization and nutrient regeneration in Airds Bay.

\subsection{Benthic Carbon and Nutrient Turnover in a Highly Irrigated Coastal Sediment}

A global compilation of available in situ TOE measurements predicts an average benthic $\mathrm{O}_{2}$ consumption rate of $13.2 \mathrm{mmol} \mathrm{m}^{-2}$ day $^{-1}$ for sediments at water depth of $65 \mathrm{~m}$ (Glud 2008). This value is bracketed by our measurements in Airds Bay (TOE: $14.9 \mathrm{mmol} \mathrm{m}^{-2}$ day $^{-1}$ and EOE: $13.1 \mathrm{mmol} \mathrm{m}^{-2}$ day $^{-1}$ ) that also are intermediary to the wide range of previously published values from sea lochs of similar water depths in West Scotland (6-28 mmol m${ }^{-2}$ day $\left.^{-1}\right)^{1}$ (Overnell et al. 1996; Loh et al. 2008a; Nickell et al. 2003; Cathalot et al. 2012). The average RQ as inferred from the concurrent exchange rates of $\mathrm{O}_{2}$ and DIC is close to unity $(1.03 \pm 0.11)$. This implies that, on a scale of the chamber enclosed area $\left(900 \mathrm{~cm}^{2}\right)$, the reduced equivalents that are being released during anaerobic degradation are being balanced by a concurrent oxidation by $\mathrm{O}_{2}$, and that $\mathrm{O}_{2}$ consumption is a good proxy for the total benthic carbon mineralization rate, also in these sediments.

The benthic mineralization in Scottish lochs is being sustained partly by local pelagic primary production and partly by terrestrially produced material that is supplied by riverine run-off (Loh et al. 2008b, 2010). To our knowledge, there are no recent assessments of primary production or sedimentation for Loch Etive. But older seasonal studies in Airds Bay estimated an annual mesotrophic gross primary production of $70 \mathrm{~g} \mathrm{C} \mathrm{m}^{-2}$ year $^{-1}$ (16.0 mmol C m${ }^{-2}$ day $^{-1}$ ) (Wood et al. 1973) and an annual sedimentation rate of $247 \mathrm{~g} \mathrm{C}^{-1}$ $\mathrm{m}^{2}$ year $^{-1}$ (56.4 mmol C m${ }^{-2} \mathrm{day}^{-1}$ ) (Ansell 1974), suggesting substantial supply of terrestrial material and sediment focusing in the basin.

The measured organic content at $10 \mathrm{~cm}$ sediment depth equates to an organic carbon (OC) content of $4.2 \%$ dry weight assuming that $40 \%$ of the organic matter consists of carbon. This aligns well with previous OC measurements of $4.9 \%$ in surface sediments of Airds Bay (Loh et al. 2008b). The sedimentation rate in central Airds Bay has been assessed previously using a profile of excess ${ }^{210} \mathrm{~Pb}$ and estimated to equal $0.59 \mathrm{~cm}$ year ${ }^{-1}$ (Overnell 2002). Using this information and applying the measured porosity ( $0.88 \mathrm{vol}$ :vol) and sediment density $\left(2.7 \mathrm{~g} \mathrm{~cm}^{-3}\right)$ at $10 \mathrm{~cm}$ sediment depth, the annual carbon burial rate amounts to $95 \mathrm{~g} \mathrm{~m}^{-2}$ year $^{-1}\left(21.4 \mathrm{mmol} \mathrm{m}^{-2}\right.$ day $\left.^{-1}\right)$. Our benthic mineralization carbon rates were obtained in autumn and cannot be directly extrapolated across seasons. However, acknowledging seasonal (and interannual) variation in the production and the supply of organic material, adding our measurement of benthic carbon mineralization ( $\sim 15 \mathrm{mmol} \mathrm{m}^{-2} \mathrm{day}^{-1}$; Table 1$)$ and the derived carbon preservation rate gives a total sedimentation rate of $161 \mathrm{~g} \mathrm{C} \mathrm{m}^{-2}$ year $^{-1}$ which scale to the estimated sedimentation rate of Ansell (1974). Based on these figures we can calculate a carbon burial efficiency of $\sim 59 \%$ which is consistent with the high sedimentation rate and substantial terrestrial inputs (Canfield 1994; Ståhl et al. 2004; Blair and Aller 2012).

Detailed investigation of sedimentary $\delta^{13} \mathrm{C}$ values and lignin content along transects in Loch Etive (and other sea lochs in the area) concluded that the terrestrial material contributed significantly to the sediment inventory of organic material (Loh et al. 2002, 2008a, b). The authors also identified a fraction of terrestrial material that was highly

\footnotetext{
1 Including values from areas not affected by fish farming and excluding a previously published laboratorydetermined value from Airds Bay of $52.3 \mathrm{mmol} \mathrm{m}^{-2}$ day ${ }^{-1}$ (Overnell et al. 1996) which we consider to be untrustworthy.
} 
labile with low $\mathrm{C}-\mathrm{N}$ ratios and that this fraction apparently was efficiently degradedespecially in the central Airds Bay (Loh et al. 2008a). Furthermore, the rate constant for the degradation of refractory lignin was highly elevated in Airds Bay (Loh et al. 2008a). These observations and the fact that the benthic $\mathrm{O}_{2}$ consumption exceeds the local primary production strongly suggest that terrestrial carbon supply was important in sustaining the benthic community and that the turnover of refractory organic material was stimulated in these sediments. Sediment reworking and dynamic redox conditions have been shown to stimulate degradation of organic material (Aller 1994; Kristensen and Holmer 2001; Reimers et al. 2013; Aller 2014). The numerous burrows being intensively irrigated by $A$. filiformis induce highly dynamic redox conditions in the upper sediment layers, and this may indeed have facilitated further degradation of terrestrial material than would otherwise be expected in these high-deposition environments. Despite an overall RQ that is close to unity, the high spatial and temporal variation in benthic $\mathrm{O}_{2}$ availability implies an extensive microscale variation in the redox condition creating a dynamic mosaic of concurrently ongoing reductive and oxidative microbial and chemical pathways within the surface sediment. This has important implication for the regeneration and the exchange of nutrients.

Given the relatively high mineralization rates and the dynamic redox condition, most $\mathrm{N}_{2}$ production in these sediments can presumably be ascribed to denitrification rather than anammox (Rysggard et al. 2004; Trimmer et al. 2013; Devol 2015). The denitrification rate $\left(2.0 \pm 1.1 \mathrm{mmol} \mathrm{N} \mathrm{m}^{-2} \mathrm{day}^{-1}\right)$, as inferred from the net release of $\mathrm{N}_{2}$, is in the high end of available measurements for coastal sediments of similar reactivity (Herbert 1999; Eyre and Ferguson 2009; Devol 2015) and could not be sustained by the relatively moderate $\mathrm{NO}_{3}{ }^{-}$uptake from the bottom water $\left(0.43 \pm 0.42 \mathrm{mmol} \mathrm{N} \mathrm{m}^{-2} \mathrm{day}^{-1}\right)$. It follows that at least $80 \%$ of the denitrification was coupled to nitrification. Assuming, for the sake of argument, that the organic material being mineralized had an element composition close to Redfield ratio (C-N-P 106:16:1) the DIC release rate would correspond to an ammonification of $2.3 \pm 0.5 \mathrm{mmol} \mathrm{N} \mathrm{m}{ }^{-2}$ day $^{-1}$. The benthic efflux of $\mathrm{NH}_{4}{ }^{+}$was only $20 \%$ of this value (Table 1), implying that a substantial fraction was being nitrified in the sediment. Measured $\mathrm{NO}_{3}{ }^{-}$microprofiles indeed documented nitrification just below the sediment interface (Fig. 3). But the activity was patchy, and based on simple Fickian gradient calculations, the nitrification activity at the surface on average amounted to only $0.41 \pm 0.30 \mathrm{mmol} \mathrm{N} \mathrm{m}^{-2}$ day $^{-1}$ of which $>50 \%$ diffused into the bottom water rather than being denitrified. Denitrification therefore must have been sustained to a large extent by nitrification activity in the ventilated $A$. filiformis burrows. The irrigation of oxygenated water through the complex burrows presumably facilitated an efficient oxidation of $\mathrm{NH}_{4}{ }^{+}$ and supplied $\mathrm{NO}_{3}{ }^{-}$for denitrification in the surrounding sediment. Given the burrow geometry and the ongoing irrigation, $\mathrm{NO}_{3}{ }^{-}$that in the first case would have been released to the central cavity or the burrows could subsequently be denitrified further downstream, as the water gradually became depleted in $\mathrm{O}_{2}$ and passed the burrow system. The activity of A. filiformis therefore enhanced the nitrification and the coupled denitrification making the sediment an efficient sink for bioavailable nitrogen. A preferential stimulation of coupled denitrification has previously been documented for ventilated U-shaped burrows of the amphipod Corophium volutator (Pelegri and Blackburn 1994, 1996; Rysgaard et al. 1995) and the thalassinidean shrimp Typaea australiensis (Webb and Eyre 2004).

The chamber incubations revealed a consistent efflux of $\mathrm{PO}_{4}{ }^{3-}(0.29 \pm 0.26 \mathrm{mmol} \mathrm{P}$ $\mathrm{m}^{-2}$ day $^{-1}$ ) that on average exceeded the expected release associated with the degradation of organic material having a Redfield C-P ratio $\left(0.14 \mathrm{mmol} \mathrm{P} \mathrm{m}^{-2}\right.$ day $\left.^{-1}\right)$. The difference was, however, not statistically significant, and the deposition and mineralization of organic 
$\mathrm{P}$ are not temporally coupled to the benthic release of $\mathrm{PO}_{4}{ }^{3-}$ (Jensen et al. 1995). It is well established that $\mathrm{Fe}$ oxyhydroxides efficiently adsorb $\mathrm{PO}_{4}{ }^{3-}$, that upon reduction is released, typically in a ratio of 1:3 (Fe-P) (Gunners and Blomqvist 1997). The sediment of Loch Etive has a high content of iron undergoing a dynamic redox cycle (Overnell et al. 1996). It is highly plausible that fauna-induced particle mixing and advection lead to transient reduction of iron oxides in certain areas of the burrows, and a subsequent release of $\mathrm{PO}_{4}{ }^{3-}$, that was being advected out of the burrow system with the $\mathrm{O}_{2}$-depleted water. However, the adsorption and desorption of $\mathrm{PO}_{4}{ }^{3-}$ at the highly dynamic redox conditions of the burrow environment are complicated, and the net result will be highly dependent on bottom water $\mathrm{O}_{2}$ availability and deposition dynamics. Furthermore, riverine sources of non-organic and particle-bound $\mathrm{PO}_{4}{ }^{3-}$ could contribute to sedimentary inventory of $\mathrm{P}$ in Loch Etive (Benitez-Nelson 2000).

The average ratio between the efflux of DSi and DIC is 0.21 . This is somewhat higher than the value expected for the degradation of freshly deposited pelagic diatoms, which would be on the order of 0.13 (Brzezinski 1985). The elevated release of DSi could reflect that the material undergoing mineralization is enriched in Si compared to fresh pelagic diatoms (Jahnke and Jahnke 2000) or additional sedimentary supply of Si from various terrestrial sources (Conley 2002) entering complex redox-dependent dissolution kinetics (Aller 2014). In any case, in situ chamber incubations typically provide markedly higher DSi fluxes as compared to exchange rates derived from porewater calculations and shipboard incubations and this has generally been ascribed to bioirrigation (Berelson et al. 2003; Hammond et al. 2004; Tréguer and De La Rocha 2013). The high infauna activity may very well have facilitated a high efflux of DSi in the sediments of Airds Bay.

\subsection{Outlook and Perspectives}

By combining laboratory-based planar optode investigations with three different in situ approaches for assessing benthic solute exchange, we have provided a unique integrative assessment of benthic carbon mineralization and nutrient regeneration in the coastal, faunarich sediment of Loch Etive. The in situ investigations only target a confined period, but demonstrate the extensive temporal and spatial variation in benthic mineralization and derived solute exchange at the seabed. Laboratory-based investigations and discrete sampling have provided important insight into the mechanics of early diagenesis, and such approaches will remain essential in future studies. However, we also need to better appreciate the implications of naturally occurring environmental events, dynamics and spatial variations which too often are ignored by standard measuring procedures. Coastal sediments are highly dynamic and exhibit an extensive variation on several spatial scales, and we still have poor understanding on how this interrelates to the overall biogeochemical functioning of the system. This applies to not only cohesive muddy sediments, which traditionally have attracted most attention, but also permeable sands, fluid beds and hard bottom substrates. Only by fully appreciating this complexity of temporal dynamics and spatial heterogeneity, and as important, by assessing their scales correctly, can we arrive at representative mean values for specific benthic environments. To tackle these challenges, we need to further reinforce our efforts in developing observational platforms and measuring approaches for realising integrated process-oriented in situ studies.

Acknowledgments We thank Tim Brand, Anni Glud, Andy Reynolds and John Polanski for excellent technical assistance during the study and the captains and ship crews of R/V Calanus and R/V Soel Mara as well as the Lorn \& Island Hospital for providing accesses to their CT scanner. The study was financially 
supported by the UK Natural Environmental Research Council (NERC, NE/F018612/1, NE/F0122991/1, NE/G006415/1, NE/H525303/1), The Danish National research Council (FNU; 0602-02276B), The European Research Council (ERC) under the European Union's Horizon 2020 research and innovation programme (Grant Agreement No. 669947; HADES-ERC and Grant Agreement No. 267233, OXYGEN), The Australian Research Council (ARC; DP150101281, DP0878568, DP160100248) and the National Science Foundation (USA, OCE-1334848). We appreciate the constructive comments of two anonymous reviewers which helped us in improving the manuscript.

Open Access This article is distributed under the terms of the Creative Commons Attribution 4.0 International License (http://creativecommons.org/licenses/by/4.0/), which permits unrestricted use, distribution, and reproduction in any medium, provided you give appropriate credit to the original author(s) and the source, provide a link to the Creative Commons license, and indicate if changes were made.

\section{References}

Aller RC (1994) Bioturbation and remineralization of sedimentary organic-matter-effects of redox oscillation. Chem Geol 114:331-345

Aller RC (2014) Sedimentary diagenesis, depositional environments, and benthic fluxes. In: Holland HD, Turekian KK (eds) Treatise on geochemistry, vol 8, 2nd edn. Elsevier, Oxford, pp 293-334

Anderson LG, Hall POJ, Iverfeldt Å, Rutgers van der Loeff MM, Sundby B, Westerlund SFG (1986) Benthic respiration measured by total carbonate production. Limnol Oceanogr 31:319-329

Ansell AD (1974) Sedimentation of organic detritus in Loch Etive and Crean, Argyll, Scotland. Mar Biol 27:263-273

Archer D, Devol A (1992) Benthic oxygen fluxes on the Washington shelf and slope: a comparison of in situ microelectrode and chamber flux measurements. Limnol Oceanogr 37:614-629

Attard KM, Stahl H, Kamenos NA, Turner G, Burdett HL, Glud RN (2015) Benthic oxygen exchange in a live coralline algal bed and an adjacent sandy habitat: an eddy covariance study. Mar Ecol Prog Ser 535:99-115

Austin WEN, Inall ME (2002) Deep-water renewal in a Scottish fjord: temperature, salinity and oxygen isotopes. Polar Res 21:251-258

Benitez-Nelson CR (2000) the biogeochemical cycling of phosphorous in marine systems. Earth Sci Rev 51:109-135

Berelson W, McManus J, Coale K, Johnson K, Burdige D, Kilgore T, Colodner D, Chavez F, Kudela R, Boucher J (2003) A time series of benthic flux measurements from Monteray Bay, CA. Cont Shelf Res 23:457-481

Berelson WM, McManus J, Severmann S, Reimers CE (2013) Benthic flux of oxygen and nutrients across Oregon/California shelf sediments. Cont Shelf Res 55:66-75

Berg P, Huettel M (2008) Monitoring the seafloor using the noninvasive eddy correlation technique: integrated benthic exchange dynamics. Oceanogr 21:164-167

Berg P, Røy H, Felix Jannsen, Meyer V, Jørgensen BB, Huettel M, de Beer D (2003) Oxygen uptake by aquatic sediments measured with a novel non-invasive eddy-correlation technique. Mar Ecol Ser 261:75-83

Berg P, Røy H, Wiberg PL (2007) Eddy correlation flux measurements: the sediment surface area that contributes to the flux. Limnol Oceanogr 52(4):1672-1684

Berg P, Glud RN, Hume A, Stahl H, Oguri K, Meyer V, Kitazato H (2009) Eddy correlation measurements of oxygen uptake in deep ocean sediments. Limnol Oceanogr Methods 7:576-584

Berg P, Long MH, Huettel M, Rheuban JE, McGlathery KJ, Howart RW, Foream KH, Giblin AF, Marino R (2013) Eddy correlation measurements of oxygen fluxes in permeable sediments exposed to varying current flow and light. Limnol Oceanogr 58:1329-1343

Berg P, Reimers CE, Rosman JH, Huettel M, Delgard ML, Reidenbach MA, Ozkan-Haller HT (2015) Technical note: time lag correction of aquatic eddy covariance data measured in the presence of waves. Biogeosci 12:6721-6735

Blair NE, Aller RC (2012) The fate of terrestrial Continen. Ann Rev Mar Sci 4:401-423

Boudreau BP, Jr. Guinasso NL (1982) The influence of a diffusive sublayer on the aggregation, dissolution and diagenesis at the seafloor. In: Fanning KA, Manheim FT (eds) The dynamic environment at the ocean floor. Lexington Press, San Francisco, pp 115-140

Brzezinski MA (1985) The Si:C:N ratio of marine diatoms: interspecific variability and the effects of some environmental variables. J Phycol 21:347-357 
Canfield DE (1994) Factors influencing organic carbon preservation in marine sediments. Chem Geol 114:315-329

Canfield DE, Jørgensen BB, Fossing H, Glud RN, Gundersen JK, Ramsing NB, Thamdrup B, Hansen JW, Nielsen NP, Hall POJ (1993) Pathways of organic carbon oxidation in three continental margin sediments. Mar Geol 113:27-40

Cathalot C, Rabouille C, Pastor L, Deflandre B, Viollier E, Buscail R, Gremare A, Treignier C, Pruski A (2010) Temporal variability of carbon recycling in coastal sediments influenced by rivers: assessing the impact of flood inputs in the Rhone River prodelta. Biogeosciences 7:1187-1205

Cathalot C, Lansard B, Hall POJ, Tengberg A, Almroth-Rosell E, Apler A, Calder L, Bell E, Rabouille C (2012) Spatial and temporal variability of benthic respiration in a Scottish sea loch impacted by fish farming: a combination of In situ techniques. Aquat Geochem 18:515-541

Conley DJ (2002) Terrestrial ecosystems and the global biogeochemical silica cycle. Glo Biogeochem cycle 16:1121

Dedieu K, Rabouille C, Thouzeau G, Jean F, Chauvand L, Clavier J, Mesnage V, Ogier S (2007) Benthic $\mathrm{O}_{2}$ distribution and dynamics in a Mediterranean lagoon (Thau, France): an in situ microelectrode study. Estuar Coas Shelf Sci 72:393-405

Devol AH (2015) Denitrification, anammox, and $\mathrm{N}_{2}$ production in marine sediments. Annu Rev Mar Sci 7:403-423

Donis D, Holtappels M, Noss C, Cathalot C, Hancke K, Polsenaere P, Wenzhoefer F, Lorke A, Meysman FJR, Glud RN, McGinnis DF (2015) An assessment of the precision and confidence of aquatic eddy correlation measurements. J Atmos Ocean Technol 32:642-655

Edwards A, Edelstein DJ (1977) Deep water renewal of Loch Etive: a three basin Scottish fjord. Estuar Coast Mar Sci 5:575-595

Eyre BD, Ferguson AJP (2009) Denitrification efficiency for defining critical loads of carbon in shallow coastal ecosystems. Hydrobiologia 629:137-146

Eyre BD, Rysgaard S, Dalsgaard T, Christensen PB (2002) Comparison of isotope pairing and $\mathrm{N}_{2}: \mathrm{Ar}$ methods for measuring denitrification-assumptions, modifications, and implications. Estuaries 25:1077-1087

Forster S, Glud RN, Gundersen JK, Huettel M (1999) In situ study of bromide tracer and oxygen flux in coastal sediments. Estua Coast Shelf Science 49:813-827

Frederiksen MS, Glud RN (2006) Oxygen dynamics in the rhizosphere of Zostera marina: a two-dimensional planar optode study. Limnol Oceanogr 51:1072-1083

Gattuso J-P, Frankignoulle M, Wollast R (1998) Carbon and carbonate metabolism in coastal aquatic ecosystems. Annu Rev Ecol Syst 29:405-434

Glud RN (2008) Oxygen dynamics of marine sediments. Mar biol Res 4:243-289

Glud RN, Gundersen JK, Jørgensen BB, Revsbech NP, Schulz HD (1994) Diffusive and total oxygen uptake of deep-sea sediments in the eastern South Atlantic Ocean: in situ and laboratory measurements. Deep Sea Res 41:1767-1788

Glud RN, Gundersen JK, Revsbech NP, Jørgensen BB, Hüttel M (1995) Calibration and performance of the stirred flux chamber from the benthic lander Elinor. Deep Sea Res 42:1029-1042

Glud RN, Ramsing NB, Gundersen JK, Klimant I (1996) Planar optrodes, a new tool for fine scale measurements of two dimensional O2 distribution in benthic communities. Mar Ecol Prog Ser 140:217-226

Glud RN, Gundersen JK, Røy H, Jørgensen BB (2003) Seasonal dynamics of benthic $\mathrm{O}_{2}$ uptake in a semi enclosed bay: importance of diffusion and fauna activity. Limnol Oceanogr 48:1265-1276

Glud RN, Berg P, Fossing H, Jørgensen BB (2007) Effects of the diffusive boundary layer (DBL) on benthic mineralization and $\mathrm{O}_{2}$ distribution: a theoretical model analysis. Limnol Oceanogr 52:547-557

Glud RN, Stahl H, Berg P, Wenzhöfer F, Oguri K, Kitazato H (2009a) In situ microscale variation in distribution and consumption of $\mathrm{O}_{2}$ : a case study from a deep ocean margin sediment (Sagami Bay, Japan). Limnol Oceanogr 54:1-12

Glud RN, Thamdruop B, Stahl H, Wenzhöfer F, Glud A, Nomaki H, Oguri K, Revsbech NP, Kitazato H (2009b) Nitrogen cycling in a deep ocean margin sediment (Sagami bay, Japan). Limnol Oceanogr 54:723-734

Gundersen JK, Ramsing NB, Glud RN (1998) Predicting the signal of oxygen microsensors from physical dimensions, temperature, salinity, and oxygen concentrations. Limnol Oceanogr 43:1932-1937

Gunners A, Blomqvist S (1997) Phosphate exchange across the sediment-water interface when shifting from anoxic to oxic conditions - an experimental comparison of fresh and brackish-marine systems. Biogeochem 37:203-226

Hammond DE, Cummins KM, McManus J, Berelson WM, Smith G (2004) Methods for measuring benthic nutrient flux on the Californian Margin: comparing shipboard core incubations to in situ lander results. Limnol Oceanogr Methods 2:146-159 
Herbert RA (1999) Nitrogen cycling in coastal marine ecosystems. FEMS Microbiol Rev 23:563-590

Holst G, Grunwald B (2001) Luminescence lifetime imaging with transparent oxygen optodes. Sens Actuat B 75:78-90

Holst G, Kohls O, Klimant I, König B, Kühl M, Richter T (1998) A modular luminescence lifetime imaging system for mapping oxygen distribution in biological samples. Sens Actuat B 51:163-170

Holtappels M, Glud RN, Donis D, Liu B, Hume A, Wenzhöfer Kuypers MMM (2013) Effects of transient bottom water currents and oxygen concentrations on benthic exchange rates as assessed by eddy correlation measurements. J Geophys Res Oceans 118:1157-1169

Holtappels M, Christian N, Hancke K, Cathalot C, McGinnis DF, Lorke A, Glud RN (2015) Aquatic eddy correlation: quantifying the artificial flux caused by stirring sensitive $\mathrm{O}_{2}$ sensors. PLoS One 10(1): 0116564

Hume AC, Berg P, McGlathery KJ (2011) Dissolved oxygen fluxes and ecosystem metabolism in an eelgrass (Zostera marina) meadow measured with the eddy correlation technique. Limnol Oceanogr $56: 86-96$

Inoue T, Glud RN, Stahl H, Hume A (2011) Comparison of three methods for assessing in situ friction velocity: a case study from Loch Etive, Scotland. Limnol Oceanogr Methods 9:275-287

Jahnke RA (2001) Constraining organic matter cycling with benthic fluxes. In: Boudreau BP, Jørgensen BB (eds) The benthic boundary layer. Oxford Uinversity Press, Oxford

Jahnke RA, Christensen MB (1989) A free vehicle benthic chamber instruments for sea-flor studies. Deep Sea Res 36:625-637

Jahnke RA, Jahnke DB (2000) Rates of C, N, P ad Si recycling and denitrification at the US Mid-Atlantic continental slope depocenter. Deep Sea Res I 47:1405-1428

Jahnke BD, Jahnke RA (2008) Dynamics of seafloor processes-advances from benthic observing technologies. Oceanography 21:162-163

Jahnke RA, Reimers CE, Craven DB (1990) Intensification of recycling of organic matter at the sea floor near ocean margins. Nature 348:50-54

Jensen HS, Mortensen PB, Andersen FO, Rasmussen E, Jensen A (1995) Phosphorous cycling in a coastal marine sediment, Aarhus Bay, Denmark. Limnol Oceanogr 40:908-917

Johnson KM, Sieburth JM, Williams PJL, Brädström L (1987) Coulometric total carbon dioxide analysis for marine studies: automation and calibration. Mar Chem 21:117-133

Jørgensen BB, des Marais DJ (1990) The diffusive boundary layer and the oxygen uptake of sediments and detritus. Limnol Oceanogr 35:1343-1355

Kristensen E, Holmer M (2001) Decomposition of plan materials in marine sediments exposed to different electron acceptors $\left(\mathrm{O}_{2}, \mathrm{NO}_{3}{ }^{-}, \mathrm{SO}_{4}{ }^{2-}\right)$, with emphasis on substrate origin, degradation kinetics and the role of bioturation. Geochim Cosmochim Acta 65:419-433

Krom MD, Berner RA (1983) A rapid method for the determination of organic and carbonate carbon in geological samples. J Sediment Petrol 53:660-663

Kühl M, Steuckart C, Eickert G, Jeroschewski P (1998) A $\mathrm{H}_{2} \mathrm{~S}$ microsensor for profiling biofilms and sediments: application in an acidic lake sediment. Aquat Microb Ecol 15:201-209

Lee X, Massman W, Law B (2004) Handbook of micrometeorology: A guide for surface flux measurement and analysis. Kluwer Academic Publishers, Berlin

Liu KK, Kang CK, Kobari T, Liu H, Rabouille C, Fennel K (2014) Biogeochemistry and ecosystems of continental margins in the western North Pacific Ocean and their interactions and responses to external forcing - an overview and synthesis. Biogeosciences 11:7061-7075

Loh PS, Reeves AD, Overnell J, Harvey SM, Miller AEJ (2002) Assessment of terrigenous organic carbon input to the total organic carbon in sediments from Scottish transitional waters (sea lochs): methodology and preliminary results. Hydrol Earth Syst Sci 6:959-970

Loh PS, Miller AEJ, Reves AD, Harvey SM, Overnell J (2008a) Assessing the biodegradability of terrestrially-derived organic matter in Scottish sea loch sediments. Hydrol Earth Syst Sci 12:811-823

Loh PS, Reeves AD, Harvey SM, Overnell J, Miller AEJ (2008b) The fate of terrestrial organic matter in two Scottish sea lochs. Estuar Coast Shelf Sci 76:566-579

Loh PS, Reeves DA, Miller AEJ, Harvey SM, Overnell J (2010) Sediment fluxes and carbon budget in Loch Creran western Scotland. In: Howe JA, Howe WEN, Forwick M, Paetzel M (eds) Fjord systems ad archives, vol 344. Geo Soc, special publications, London, pp 103-124

Loo LO, Johnson PR, Sköld M, Karlsson O (1996) Passive suspension feeding in Amphiura filiformis (Echinodermata:Ophiuroidea): feeding behavior in flume flow and potential feeding rate of field populations. Mar Ecol Prog Ser 139:143-155

Lorrai C, McGinnins DF, Berg P, Brand A, Wueest A (2010) Application of oxygen eddy correlation in aquatic systems. J Atmos Ocean Technol 27:1533-1546 
McGinnis DF, Berg P, Brand A, Lorrai C, Edmonds TJ, Wüest A (2008) Measurements of eddy correlation oxygen fluxes in shallow freshwaters: towards routine applications and analysis. Geophys Res Lett 35:L04403

McGinnis DF, Cherednichenko S, Sommer S, Berg P, Rovelli L, Schwarz R, Glud RN, Linke P (2011) Simple, robust eddy correlation amplifier for aquatic dissolved oxygen and hydrogen sulfide flux measurements. Limnol Oceanogr Methods 9:340-347

Munksby N, Benthien M, Glud RN (2002) Flow-induced flushing of relict tube structures in the central Skagerak (Norway). Mar Biol 141:939-945

Nickell LA, Black KD, Hughes DJ, Overnell J, Brand T, Nickell TD, Breuer E, Harvey M (2003) Bioturbation, sediment fluxes and benthic community structure around salmon cage farm in Loch Creran, Scotland. J Exp Mar Biol Ecol 285-286:221-233

Nixon SW, Ammerman JW, Atkinson LP, Berounsky VM, Billen G, Boicourt WC, Boynton WR, Church TM, Ditoro DM, Elmgren R, Garber JH, Giblin AE, Jahnke RA, Owens NJP, Pilson MEQ, Seitzinger SP (1996) The fate of nitrogen and phosphorus at the land-sea margin of the North Atlantic Ocean. Biogeochemistry 35:141-180

Overnell J (2002) Manganese and iron profiles during early diagenesis in Loch Etive, Scotland. Application of two diagenetic models. Estuar Coast Mar Sci 54:33-44

Overnell J, Harvey MS, Parkes RJ (1996) A biogeochemical comparison of sea loch sediments. Manganese and iron contents, sulphate reduction and oxygen uptake rates. Ocean Acta 19:41-55

Overnell J, Brand T, Bourgeois W, Statham PJ (2002) Manganese dynamics in the water column of the upper basin of Loch Etive, a Scottish fjord. Estuar Coast Mar Sci 55:481-492

Pelegri SP, Blackburn TH (1994) Bioturbation effects of the amphipod Corophium volutator on microbial nitrogen transformations in marine sediments. Mar Biol 121:253-258

Pelegri SP, Blackburn TH (1996) Nitrogen cycling in lake sediments bioturbated by Chironomus plumosus larvae, under different degrees of oxygenation. Hydrobiologica 325:231-238

Rasmussen H, Jørgensen BB (1992) Microelectrode studies of seasonal oxygen uptake in a coastal sediment: role of molecular diffusion. Mar Ecol Prog Ser 81:289-303

Reimers CE, Fisher KM, Merewether R, Smith KL Jr, Jahnke R (1986) Oxygen profiles measured in situ in deep ocean sediments. Lett Nat 320:741-744

Reimers CE, Alleau Y, Sauer JE, Delaney J, Girguis PR, Schrader PS, Stecher HA (2013) Redox effects on the microbial degradation of refractory organic matter in marine sediments. Geochim Cosmochim Acta 121:582-598

Revsbech NP (1989) An oxygen microelectrode with a guard cathode. Limnol Oceanogr 34:474-478

Revsbech NP, Glud RN (2009) Biosensor for laboratory and lander-based analysis of benthic nitrate plus nitrite distribution in marine environments. Limnol Oceanogr Methods 7:761-770

Rysgaard S, Christensen PB, Nielsen LP (1995) Seasonal variation in nitrification and denitrification in estuarine sediment colonized by benthic microalgae and bioturbating infauna. Mar Ecol Prog Ser 126:111-121

Rysggard S, Glud RN, Risgaard-Petersen N, Dalsgaard T (2004) Denitrification and anammox activity in Arctic sediments. Limnol Oceanogr 49:1493-1502

Smith JRKL, Glatts RC, Baldwin RJ, Beaulieu SE, Uhlman AH, Horn RC, Reimers CE (1997) An autonomous bottom-transecting vehicle for making long time-series measurements of sediment community oxygen consumption to abyssal depths. Limnol Oceanogr 42:1601-1612

Smith WS, Bianchi TS, Allison M, Savage C, Galy V (2015) High rates of organic carbon burial in fjord sediments globally. Nat Geosci 8:450-454

Ståhl H, Tengberg A, Brunnegård J, Bjørnbom E, Forbes TL, Josefson AB, Kaberi HG, Hassellöv IMK, Olsgard F, Ross P, Hall POJ (2004) Factors influencing organic carbon recycling and burial in Skagerrak sediments. J Mar Res 62:867-907

Stieglizz T, Ridd P, Müller P (2000) Passive irrigation and functional morphology of crustacean burrows in a tropical mangrove swamp. Hydrobiologica 421:69-76

Tengberg A, Hovdenes J, Andersson HJ, Brocandel O, Diaz R, Herbert D, Arnerich T, Huber C, Kortzinger A, Khripounoff A, Rey F, Ronning C, Schimanski J, Sommer S, Stangelmayer A (2006) Evaluation of a life-time based optode to measure oxygen in aquatic systems. Limnol Oceanogr Methods 4:7-17

Thamdrup B, Fossing H, Jorgensen B (1994) Manganese, iron, and sulfur cycling in a coastal marine sediment, Aarhus Bay, Denmark. Geochim Cosmochim Acta 58:5115-5129

Therkildsen MS, Lomstein BA (1993) Seasonal-variation in net benthic c-mineralization in a shallow estuary. FEMS Microbiol Biol 12:131-142

Thouzeau G, Grall J, Clavier J, Chauvaud L, Jean F, Leynaert A, Longphuit S, Amice E, Amouroux D (2007) Spatial and temporal variability of benthic biogeochemical fluxes associated with macrophytic and macrofaunal distributions in the Thau lagoon (France). Estaur Coast Shelf Sci 72:432-446 
Toussaint F, Rabouille C, Cathalot C, Bombled B, Abchichte A, Aouji O, Buchholtz G, Clemencon A, Geyskens N, Repecaud M (2014) A new device to follow temporal variations of oxygen demand in deltaic sediments: the LSCE benthic station. Limnol Oceanogr 12:729-741

Tréguer PJ, De La Rocha CL (2013) The world ocean silica cycle. Annu Rev Mar Sci 5:47501

Trimmer M, Engstrom P, Thamdrup B (2013) Stark contrast in denitrification and anammox across the deep Norwegian Trench in skagerrrak. Appl Environ Microb 79:7381-7389

Ullmann WJ, Aller RC (1982) Diffusion coefficients in nearshore marine sediments. Limnol Oceanogr 27:552-556

Vopel K, Thistle D, Rosenberg R (2003) Effect of the brittle star Amphiura filiformis (Amphiuridae, Echinodermata) on oxygen flux into the sediment. Limnol Oceanogr 48:2034-2045

Webb AP, Eyre BD (2004) The effect of natural populations of the burrowing thalassinidean shrimp Typaea australiensis on sediment irrigation and benthic metabolism, nutrient fluxes and denitrification. Mar Ecol Prog Ser 268:205-220

Wollast R (1993) Interactions of carbon and nitrogen cycles in the coastal zone. In: Wollast R, Mackenzie FT, Shou L (eds) Interactions of $\mathrm{C}, \mathrm{P}$ and $\mathrm{S}$ biogeochemical cycles and global changes. Springer, Berlin, pp 195-210

Wood BJB, Tett PB, Edwards A (1973) An introduction to the phytoplankton, primary production and relevant hydrography of Loch Etive. J Ecol 61:569-585

Woodley JD (1975) The behavior of some amphiurid brittlestars. J Exp Mar Biol Ecol 18:29-46

Woulds C, Bouillon S, Cowie GL, Drake E, Middelburg JJ , Witte U (2016) Patterns of carbon processing at the seafloor: the role of faunal and microbial communities in moderating carbon flows. Biogeosciences $13: 4343-4357$ 